\title{
ALGUNAS PROPUESTAS GRADUALES DE DEMOCRATIZACIÓN DEL PROCEDIMIENTO DE REFORMA CONSTITUCIONAL
}

\author{
DIEGO GONZÁLEZ CADENAS
}


SUMARIO

1. INTRODUCCIÓN. 2. CONSTITUCIÓN Y PARTICIPACIÓN CIUDADANA. 3. LA REFORMA DE LOS REGLAMENTOS DE LAS CÁMARAS. 3.1. PROHIBICIÓN DEL USO DEL PROCEDIMIENTO DE URGENCIA Y LECTURA ÚNICA EN EL CASO DE REFORMA A TRAVÉS DEL ARTÍCULO 167. 3.2. LA INTRODUCCIÓN DE MECANISMOS PARTICIPATIVOS Y DE TRANSPARENCIA EN EL CASO DE REFORMA A TRAVÉS DEL ARTÍCULO 168. 4. REPLANTEAMIENTO POR ARTÍCULOS DEL PROCEDIMIENTO DE REFORMA ESTABLECIDO EN LA CONSTITUCIÓN. 4.1. INTRODUCCIÓN DE LA INICIATIVA CIUDADANA CONSTITUCIONAL Y CONSTITUYENTE. 4.2. OBLIGATORIEDAD DE REFERÉNDUM EN CASO DE ACTIVACIÓN DEL PROCEDIMIENTO DE REFORMA DEL ARTÍCULO 167 CE. 4.3. LA INNECESARIA DETERMINACIÓN DE SÓLO ALGUNOS PRECEPTOS PARA SER OBJETO DE UNA REFORMA PARCIAL POR LA VÍA DEL ARTÍCULO 168. 4.4. LA SEPARACIÓN ENTRE ÓRGANO LEGISLATIVO Y CONSTITUYENTE. 4.5. LA MAYORÍA REQUERIDA PARA LA APROBACIÓN DEL NUEVO TEXTO CONSTITUCIONAL POR PARTE DEL ÓRGANO CONSTITUYENTE. 4.6. EL CONTROL PREVIO DE CONSTITUCIONALIDAD DE LA REFORMA CONSTITUCIONAL POR PARTE DEL TRIBUNAL CONSTITUCIONAL. 4.7. LA CORRECCIÓN DEL ARTÍCULO 169. 5. UNA PROPUESTA CONCRETA DE NUEVO ARTICULADO DEL TÍTULO X. 


\title{
ALGUNAS PROPUESTAS GRADUALES DE DEMOCRATIZACIÓN DEL PROCEDIMIENTO DE REFORMA CONSTITUCIONAL
}

\author{
DIEGO GONZÁLEZ CADENAS ${ }^{1}$ \\ Universidad de Valencia
}

\section{INTRODUCCIÓN}

La metáfora de Ulises y las sirenas es bien conocida en la doctrina gracias a su popularización en la obra de Elster ${ }^{2}$. Como se recordará, antes de pasar por los dominios de las sirenas a su vuelta de Troya, Ulises ordenó a su tripulación que se cubrieran los oídos con tapones de cera y que le ataran al mástil de su barco para evitar sucumbir al canto de las sirenas. Una Constitución, en forma similar, es el instrumento del que los ciudadanos nos dotamos racionalmente para limitar nuestras acciones en un momento futuro de crisis ante los posibles los cantos de sirena de algún líder demagógico y extremista. Sin embargo, como el propio Elster señalaría más tarde, las constituciones, paradójicamente, fijan por lo normal su vocación de permanencia y atemporalidad en momentos de crisis poco adecuados para el planteamiento sosegado de una norma de tal importancia. Una buena parte de los vicios, antagonismos y lagunas de las constituciones viene marcada de inicio por este hecho. De esta forma, contrariamente a la hayekeana afirmación de que una Constitución es el amarre impuesto por Peter cuando está sobrio para Peter cuando está ebrio, el Peter que escribe la Constitución es más probable que esté ebrio que sobrio ${ }^{3}$.

1 Departamento de Derecho Constitucional, Ciencia Política y de la Administración. Facultad de Derecho. Universidad de Valencia. Avenida de los Naranjos, s/n. 46022 Valencia. Email: goncadie@ uv.es

2 Elster, J. (1984). Ulysses and the Sirens: studies in rationality and irrationality. New York: Cambridge University Press.

3 Elster, J. (2012). «The optimal design of a constituent assembly». En H. Landemore (Ed.), Collective wisdom: Principles and Mechanisms (pp. 148-172). Cambridge: Cambridge University Press, p. 151; Elster, J. (1995). Forces and mechanisms in the constitution-making process. Duke Law Journal, 45(2), p. 394.

(C) UNED. Revista de Derecho Político

N. ${ }^{\circ} 108$, mayo-agosto 2020, págs. 247-281 
Son múltiples las publicaciones académicas recientes que vienen advirtiendo acerca de la crisis de la democracia constitucional y los cambios profundos que se están y van a seguir produciéndose en las mismas ${ }^{4}$. La discusión académica actual no radica en la conveniencia o no del cambio, sino en si serán fuerzas democráticas o fuerzas extremistas las que lo protagonizarán. A mi juicio, no es todavía demasiado tarde para que sean las primeros las que lideren el cambio, también el inevitable cambio constitucional, procediendo a poner frenos y vacunas democráticas al surgimiento de fuerzas de fuerte tendencia autoritaria. Antes de que el grado de polarización política haga impracticable una reforma consensuada de la Constitución, las fuerzas democráticas tienen el deber de refundar sosegadamente el país.

La última experiencia constituyente española fue fruto de un elevado consenso entre diferencias tendencias políticas en un momento político de suma complejidad, lo que le valió para convertirse en un modelo de transición a la democracia para una parte importante de la academia internacional y numerosos países de América Latina y Europa oriental en los años 80 y 90 del siglo pasado 5 . No obstante, aunque resulta plenamente comprensible debido el momento histórico en que éste se desarrolló, no se caracterizó por la participación directa de la ciudadanía en el debate constituyente, más allá del referéndum para la ratificación de la Constitución en diciembre de 1978. Asimismo, el proceso constituyente ha sido acusado de carencia de transparencia debido al trabajo en secreto en la Ponencia encargada de preparar el anteproyecto de Constitución designada por la Comisión de Asuntos Constitucionales y Libertades Públicas del Congreso de los Diputados, y a la toma de decisiones entre representantes de diversos partidos fuera de las sesiones de debate en las Cortes ${ }^{6}$. España tiene ahora la oportunidad de volver a ser pionera en el campo de los procesos de cambio constitucional e inspirar así a múltiples países sumidos en una crisis constitucional. La ilusión compartida por un proyecto común puede únicamente generarse mediante una amplia deliberación democrática en la que se rompa la desafección constitucional que se produce entre la ciudadanía ${ }^{7}$. Ello requiere, lejos de las formulaciones oxidadas que desdeñan las posibilidades de la profundización democrática, que se diseñe un

${ }^{4}$ Ginsburg, T., \& Huq, A. Z. (Eds.). (2018). How to save a constitutional democracy. Chicago: The University of Chicago Press; Graber, M. A., Levinson, S., \& Tushnet, M. (Eds.). (2018). Constitutional Democracy in Crisis? New York: Oxford University Press; Levitsky, S., \& Ziblatt, D. (2018). How Democracies Die. New York: Crown. En nuestro sistema constitucional, sin ir más lejos, viene produciéndose una mutación constitucional derivada de los cambios en la Constitución económica de la Unión Europea. Al respecto véase Grimm, D. (2017). The Constitution of European Democracy. New York: Oxford University Press, p. 13; Maestro Buelga, G. (2017). El Estado Social 40 años después la desconstitucionalización del programa constitucional. Revista de Derecho Político, 100, 769-798; Moreno González, G. (2017). El cierre de la Constitución económica española: de la apertura de posibilidades al monismo de obligaciones. Ius Fugit, 20, 117-156.

5 Sunstein, C. (2001). Designing democracy. New York: Oxford University Press, p. 261; Elster, J. (1995). Forces and mechanisms in the constitution-making process. Duke Law Journal, 45(2), p. 30.

${ }^{6}$ Gunther, R. (1986). El proceso constituyente español. Revista de Estudios Políticos, 49, p. 46.

7 Rodrik, D. (2018). Straight talk on trade. Princeton: Princeton University Press, p. 77. 
modelo de reforma constitucional moderno, participativo, transparente e inclusivo a la altura de los tiempos a fin de aumentar el sentimiento constitucional, el conocimiento de la norma básica de nuestro ordenamiento jurídico y la cultura democrática de nuestro país ${ }^{8}$. De esta forma, llegado el momento de iniciar un procedimiento de reforma de la Constitución, es clave repensar el propio procedimiento de reforma constitucional.

En última instancia, el debate acerca de las posibilidades del cambio constitucional remite, como señalan Holmes y Sunstein, al núcleo central de la legitimidad de los sistemas constitucionales. Esto es, la legitimidad de las constituciones depende en gran medida, y paradójicamente, de la posibilidad de que éstas sean cambiadas. «Es aceptada, o amerita ser aceptada, en parte porque puede ser cambiada» ${ }^{9}$. Una parte creciente de la doctrina está fijando su atención, además, en cómo se procede a dicho proceso de cambio ${ }^{10}$. Efectivamente, como lo expresa Menéndez, «el valor jurídico y político de las normas materialmente constitucionales depende no sólo de su letra, sino decisivamente del proceso a través del cual las mismas hayan sido escritas. La legitimidad democrática no es un plus, sino un rasgo de identidad de las normas constitucionales democráticas» ${ }^{11}$. O lo que es lo mismo con otras palabras, únicamente puede hablarse, en puridad, de Constitución, cuando ésta emana del poder constituyente, esto es, cuando ha sido adoptada mediante expresión directa de la soberanía popular comprobándose así la adecuación entre voluntad popular y texto constitucional. De otra manera, podría ser considerada como Ley Fundamental o Norma Básica de organización del Estado, pero no sería correcto utilizar el término Constitución, tal y como prontamente identificaron los revolucionarios estadounidenses ${ }^{12}$. La iden-

${ }^{8}$ Hart, V. (2003). Democratic constitution-making. United States Institute of Pace, 107.

9 Holmes, S., \& Sunstein, C. (1995). The politics of constitutional revision in eastern Europe. En S. Levison (Ed.), Responding to imperfection: The theory and practice of constitutional amendment (pp. 275-306). Princeton: Princeton University Press, p. 277.

10 Albert, Richard. (2018). Constitutional Amendments. Making, Breaking, and Changing Constitutions. New York: Oxford University Press; Arato, Andrew. (2017). The Adventures of the Constituent Power: Beyond Revolutions? New York: Cambridge University Press; Eisenstadt, T. A., Levan, A. C., \& Maboudi, T. (2015). When Talk Trumps Text: The Democratizing Effects of Deliberation during ConstitutionMaking, 1974-2011. American Political Science Review, 109(3), 592-612; Landemore, H. (2015). Inclusive Constitution-Making: The Icelandic Experiment. The Journal of Political Philosophy, 23(2), 166-191; Tushnet, M. (2013). Constitution-making: an introduction. Texas Law Review, 91(7), 1983-2013; Blount, J., Elkins, Z., \& Ginsburg, T. (2012). Does the process of constitution-making matter? Annual Review of Law and Social Science, 5, 31-66; Elster, J. (2012). Clearing and strengthening the channels of constitution making. En T. Ginsburg (Ed.), Comparative constitutional desing (pp. 15-30). New York: Cambridge University Press; Saunders, C. (2012). Constitution-making in the 21st century. International Review of Law, 4, 1-10; Colón-Ríos, J. I. (2011). Carl Schmitt and constituent power in Latin American courts: The cases of Venezuela and Colombia. Constellations, 18(3), 365-388;

11 Menéndez, A. J. (2010). La Unión Europea entre el constitucionalismo democrático y la gobernanza. Revista de Estudios Políticos, (149), p. 49.

${ }^{12}$ Fritz, C. G. (2008). American Sovereigns: The People and America's Constitutional Tradition before the Civil War. New York: Cambridge University Press.

(C) UNED. Revista de Derecho Político

N. ${ }^{\circ} 108$, mayo-agosto 2020, págs. 247-281 
tificación entre el concepto de Constitución y la necesidad de ratificación popular de la misma se encuentra en las mismas raíces de la idea de Constitución desde que la Constitución de Massachusetts fuese ampliamente debatida y posteriormente ratificada en los pueblos y ciudades de Massachusetts en $1780^{13}$.

Siguiendo este principio básico, en este artículo voy a plantear una serie de reformas concretas del procedimiento de reforma constitucional establecido en la Constitución española de 1978. En primer lugar, tomando como punto de referencia los estudios que desde la doctrina española se han venido realizando acerca de la reforma del procedimiento de reforma, debatiré algunas de las implicaciones que tiene la introducción del principio de participación ciudadana en el proceso de conformación constitucional. Acto seguido, entraré directamente en materia para realizar una propuesta en dos niveles de reforma del procedimiento de reforma de la Constitución. El primer nivel que analizaré, debido a la mayor facilidad para proceder a su reforma y asumiendo que es altamente probable que únicamente se piense en la posibilidad de proceder a reformar el procedimiento de reforma de la Constitución en el marco de un proceso de reforma agravado de la Constitución, es el reglamentario y el legislativo. El segundo nivel será el propiamente constitucional. Procederé a examinar el Título X de la Constitución replanteando cada uno de los artículos en diferentes sentidos. En tercer y último lugar, cerraré el artículo sugiriendo un nuevo procedimiento de reforma constitucional en consonancia con todo lo expuesto anteriormente y manteniendo la estructura del Título X.

\section{CONSTITUCIÓN Y PARTICIPACIÓN CIUDADANA}

Entre las múltiples monografías y artículos que se han publicado en los últimos años acerca de la reforma constitucional en España, se han dedicado diversos artículos y capítulos a la cuestión que aquí nos ocupa. Una parte mayoritaria de la doctrina, partiendo de una concepción de Constitución de acuerdo con la cual el proceso por el cual se conforma es considerado secundario, cuando no irrelevante, resta importancia a la posibilidad de participación ciudadana directa o, sencillamente, no se plantea una crítica al procedimiento de reforma constitucional vigente desde esta perspectiva.

Contreras Casado apunta que el artículo 167 «no ha sufrido objeciones serias por parte de la doctrina» ${ }^{14}$, obviando, por tanto, la posibilidad de introducción de la obligatoriedad del referéndum en caso de reforma parcial de la Constitución. Tajadura Tejada defiende que en el caso en que no haya siquiera una minoría de un diez por

13 Handlin, O., \& Handlin, M. (Eds.). (1966). The popular sources of political authority. Documents on the Massachusetts Constitution of 1780. Cambridge: Harvard University Press.

${ }^{14}$ Contreras Casado, M. (2017). ¿Reformar la Reforma? Un balance crítico de los procedimientos de reforma constitucional en la Constitución española. En J. Cano Bueso \& R. Escudero Rodríguez (Eds.), Estudios en Homenaje a Alfonso Guerra. La Constitución a Examen: la Reforma de la Constitución en España (pp. 59-74). Valencia: Tirant lo Blanch, p. 64. 
ciento de los diputados que se opongan a la reforma, el referéndum es una «garantía excesiva e innecesaria» debido a que un resultado favorable en el mismo es previsible ${ }^{15}$. Otros autores, tal y como se señala en el texto editado por García Roca, apostando por la refundición de los dos procedimientos de reforma, señalan la conveniencia de mantener el referéndum obligatorio, pero únicamente en el caso de las reformas que afecten al título preliminar ${ }^{16}$. Desde una perspectiva similar, Balaguer Callejón y Trujillo Pérez plantean que el referéndum sea únicamente obligatorio en aquellas materias que afecten al título preliminar y facultativo en el resto de supuestos, condicionado a que así lo demanden una décima parte de los representantes de cualquiera de las cámaras ${ }^{17}$.

No obstante, desde el prisma constitucional democrático, la conveniencia de un referéndum de ratificación constitucional es difícilmente contestable. Desde esta perspectiva, la Constitución ha de ser reflejo de la voluntad popular, por lo que la ciudadanía habrá de intervenir en el proceso de redacción del texto y en el momento de su aprobación final ${ }^{18}$. En tanto expresión del poder constituyente, del ejercicio de la soberanía popular en momentos de cambio constitucional, la ciudadanía ha de tener necesariamente la ultima palabra, no pudiendo quedar todo el proceso enmarcado dentro del juego de los titulares del poder político ${ }^{19}$. El referéndum de ratificación constitucional es un instrumento que impide que los poderes constituidos puedan aprobar determinados preceptos contrarios a la opinión popular o que no sean coincidentes con las promesas realizadas en campaña electoral ${ }^{20}$. Tiene la virtud de alentar a los representantes para que consensuen posturas comunes e introduzcan preceptos

15 Tajadura Tejada, J. (2016). La reforma de la Constitución (arts. 166-169). En T. Freixes Sanjúan \& J. C. Gavara de Cara (Eds.), Repensar la constitución. Ideas para una reforma de la Constitución de 1978: reforma y comunicación dialógica (pp. 257-281). Madrid: Boletín Oficial del Estado, p. 267. Para una visión completa de la visión del citado autor acerca del título $\mathrm{X}$, al que me referiré en diversos apartados del presente artículo, se recomienda la consulta de Tajadura Tejada, J. (2018). La reforma constitucional: procedimientos y límites. Un estudio crítico del Título X de la Constitución de 1978. Madrid: Marcial Pons.

${ }^{16}$ García Roca, J. (Ed.). (2014). El procedimiento de reforma constitucional. Pamplona: Aranzadi.

17 Balaguer Callejón, M. L., \& Trujillo Pérez, A. J. (2018). Título X. De la reforma constitucional. En Y. Gómez Sánchez (Ed.), Estudios sobre la reforma de la Constitución de 1978 en su Cuarenta Aniversario (pp. 427-440). Pamplona: Aranzadi, p. 434.

18 Martínez Dalmau, R. (2018). Soberanía popular, poder constituyente, poder constituido. Diritto Costituzionale, (1), 71-94.

19 Colón-Ríos, J. I. (2011). Carl Schmitt and constituent power in Latin American courts: The cases of Venezuela and Colombia. Constellations, 18(3), 365-388. En igual sentido, Díez-Picazo Giménez recuerda que en modo alguno se puede hablar de Constitución de la Unión Europea puesto que los Tratados de la Unión no son la consecuencia de un acto constituyente Díez-Picazo Giménez, L. (1993). Reflexiones sobre la idea de Constitución Europea. Revista de Instituciones Europeas, (2), 533-562.

${ }^{20}$ García-Escudero Márquez, P. (2008). El procedimiento agravado de reforma de la Constitución de 1978. Revista de Derecho Político, 71-72, p. 190; Contreras Casado, M. (2017). ¿Reformar la Reforma? Un balance crítico de los procedimientos de reforma constitucional en la Constitución española. En J. Cano Bueso \& R. Escudero Rodríguez (Eds.), Estudios en Homenaje a Alfonso Guerra. La Constitución a Examen: la Reforma de la Constitución en España (pp. 59-74). Valencia: Tirant lo Blanch, p. 70.

(C) UNED. Revista de Derecho Político 
cercanos al sentir popular ${ }^{21}$. Asimismo, contrariamente a lo que se ha afirmado, las dinámicas de la voluntad del poder constituyente no se ven necesariamente reflejadas en las dinámicas de los poderes constituidos ${ }^{22}$.

Dada la fuerte crisis de representación y de legitimidad democrática existente en España ${ }^{23}$, parece entonces adecuado fomentar la participación popular en el proceso de conformación y ratificación de la norma suprema del ordenamiento jurídico. En este sentido viene pronunciándose una parte mayoritaria de la doctrina especializada en el estudio del diseño jurídico de los procesos de cambio constitucional, comúnmente conocido como constitution-making ${ }^{24}$. Entre las virtudes que se le atribuyen, destaca, en primer lugar, el incremento de la legitimidad de origen de la Constitución $^{25}$ y el sistema político ${ }^{26}$, lo que conlleva, a su vez, un aumento de la longevidad de la primera y de la estabilidad del segundo ${ }^{27}$. Asimismo, se subraya que el control y la presión ciudadana impide, por un lado, la adopción de disposiciones que limiten derechos y libertades democráticas ${ }^{28} \mathrm{y}$, por otro, propicia la introducción de normas

${ }^{21}$ Blount, J., Elkins, Z., \& Ginsburg, T. (2012). Does the process of constitution-making matter? Annual Review of Law and Social Science, 5, p. 218.

22 Sáenz Royo, E. (2016b). La regulación y la práctica del referéndum en Suiza: Un análisis desde las críticas a la institución del referéndum. Revista de Estudios Políticos, 171, p. 131. Al respecto, son múltiples los ejemplos recientes de reformas constitucionales impulsadas o defendidas por el Gobierno o por las fuerzas mayoritarias en el Parlamento que fueron rechazadas o no contaron con suficiente apoyo por parte la ciudadanía: el referéndum canadiense de 1992 acerca de un proyecto de reforma constitucional propuesto por el Gobierno federal y los gobiernos provinciales conocido como el Acuerdo de Charlottetown; el referéndum de 2003 en Colombia promovido por el presidente Álvaro Uribe por el que se plantearon 15 preguntas acerca de diversas reformas de la Constitución y de las cuales únicamente una recabó el quórum requerido del 25\%, por lo que a pesar de haber contado con la aprobación de la mayoría de los votantes las preguntas restantes no fueron aprobadas; los referéndums francés y holandés de ratificación del Tratado por el que se establecía una Constitución para Europa en 2005; el referéndum de reforma constitucional impulsado en Italia en 2006 por el Gobierno de Silvio Berlusconi por el que se planteaba una reforma de 57 artículos constitucionales; el referéndum en 2007 para reformar 65 artículos de la Constitución de Venezuela impulsado por el Partido Socialista Unificado de Venezuela; o el referéndum de reforma constitucional de Bolivia en 2016 que tenía por objeto permitir la reelección del presidente y el vicepresidente de la República.

23 Vírgala Foruria, E. (2013). Crisis de la representación y democracia directa en España. Asamblea: revista parlamentaria de la Asamblea de Madrid, 29, 11-25.

${ }^{24}$ González Cadenas, D. (2018). Democracia y procesos constituyentes. Un análisis jurídico-político. Valencia: Tirant lo Blanch, p. 187.

25 Martínez Dalmau, R. (2014). El debate sobre la naturaleza del poder constituyente. En R. Martínez Dalmau (Ed.), Teoría y práctica del poder constituyente (pp. 67-120). Valencia: Tirant lo Blanch.

${ }^{26}$ Eisenstadt, T. A., Levan, A. C., \& Maboudi, T. (2017). Constituents Before Assembly. New York: Cambridge University Press.

27 Elkins, Z., Ginsburg, T., \& Melton, J. (2009). The endurance of national constitutions. New York: Cambridge University Press.

28 Blount, J., Elkins, Z., \& Ginsburg, T. (2012). Does the process of constitution-making matter? Comparative Constitutional Design, (July), 31-66; Samuels, K. (2006). Constitution Building Processes and Democratization: A Discussion of Twelve Case Studies. Estocolmo: International Institute for Democracy and Electoral Assistance; Voigt, S. (2003). The consequences of popular participation in constitutional 
que las garanticen junto con preceptos y mecanismos innovadores que van más allá de la agenda política de las élites dirigentes y de las soluciones constitucionales tradicionales ${ }^{29}$. La propia dinámica participativa propicia la familiarización con la Constitución y facilita que los ciudadanos hagan de ella una herramienta para la defensa y ejercicio de sus derechos ${ }^{30}$. Igualmente, la participación ciudadana fomenta la inclusión de nuevos actores, movimientos y organizaciones sociales en la vida pública más allá de los partidos políticos, generando un mayor grado de pluralismo ${ }^{31}$ que, a su vez, favorece el diálogo y la consecución de acuerdos que pueden contribuir a cerrar heridas pasadas, resolver conflictos y disminuir la brecha entre diferentes sectores sociales $^{32}$.

\section{LA REFORMA DE LOS REGLAMENTOS DE LAS CÁMARAS}

Dentro del marco constitucional vigente hay un margen de maniobra considerable para establecer toda una serie de mecanismos que hagan efectivos en mayor medida los principios de participación, transparencia e inclusividad. Bastaría con proceder a reformar los artículos 146 y 147 del Reglamento del Congreso y del 152 al 159 del Reglamento del Senado. De lo contrario, nos encontraríamos ante un proceso de reforma constitucional muy similar al de hace 40 años, regulado éste en los artículos 111 y siguientes del Reglamento provisional del Congreso de los Diputados de 17 de octubre de 1977 y los artículos 119 y siguientes del Reglamento provisional del Senado de 14 de octubre de 1977, al estar regido, salvo particularidades menores ${ }^{33}$, por el actual procedimiento legislativo ordinario (artículo $147.5 \mathrm{RdC}$ ).

choice - Towards a comparative analysis. En A. Aaken, C. List, \& C. Lutge (Eds.), Deliberation and decisión (pp. 199-229). Aldershot: Ashgate.

29 Viciano Pastor, R., \& Martínez Dalmau, R. (2011). El nuevo constitucionalismo latinoamericano: fundamentos para una construcción doctrinal. Revista General de Derecho Público Comparado, 9, 23; Aparicio Wilhelmi, M. (2011). Nuevo constitucionalismo, derechos y medioambiente en las constituciones de Ecuador y Bolivia. Revista General de Derecho Público Comparado, 9, p. 9; Hart, V. (2010). Constitution making and the right to take part in a public affair. En L. E. Miller (Ed.), Framing the State in times of transition (pp. 20-54). Washington DC: United States Institute of Peace Press Books, p. 41; Ghai, Y., \& Galli, G. (2006). Constitution Building Processes and Democratization. Estocolmo: International Institute for Democracy and Electoral Assistance.

${ }^{30}$ Widner, J. (2008). Constitution writing in post-conflict settings: An overview. William E Mary Law Review, 49(4), 1519; Haysom, N. (2003). Nation-building and constitution-making in divided societies. En R. Blindenbacher \& A. Koller (Eds.), Federalism in a Changing World: Learning from Each Other (pp. 216-239). Montreal: McGill-Queen's University Press.

31 Landau, D. (2013b). Constitution-making gone wrong. Alabama Law Review, 64(5), 923-980.

32 Benomar, J. (2004). Constitution-making after conflict: lessons for Iraq. Journal of Democracy, 15(2), p. 88.

33 En esencia, cambia que la iniciativa de reforma constitucional ejercida por las Cortes, vía artículo 167, deberá ir suscrita por dos Grupos Parlamentarios o por una quinta parte de los diputados (art. 146.1 $\mathrm{RdC}$ ). En el caso del Senado, se determina que, tanto para la reforma como para la revisión constitucional, 
Por otra parte, la reforma de los reglamentos de las cámaras, viene señalando la doctrina, es perentoria por dos motivos: la confusión acerca de la «aprobación del principio» de revisión total establecido en el artículo $168.1 \mathrm{CE}^{34}$ y la ausencia de un mecanismo que permita una conciliación de las diferencias entre el Congreso y el Senado ${ }^{35}$. Es conveniente entonces aprovechar la oportunidad abierta por la necesidad de reforma de los reglamentos para introducir un procedimiento constitucional especial diferenciado del procedimiento legislativo, en línea con lo señalado por García Roca $^{36}$. Dedico los siguientes apartados a desarrollar una serie de propuestas en este sentido.

la iniciativa puede partir de cincuenta senadores que no pertenezcan al mismo grupo parlamentario (art. $151 \mathrm{RdS}$ ). Asimismo, en el caso del RdS, se establece que en el caso de que la reforma constitucional se inicie desde el Congreso, la Comisión de Constitución podrá designar una Ponencia encargada de informar el proyecto y las enmiendas presentadas al mismo y elaborará el correspondiente dictamen que será elevado al Pleno de la Cámara para su debate y votación (art. 154.2 RdS).

${ }^{34}$ Se produce una incongruencia entre lo establecido en la Constitución y los reglamentos de las cámaras. De acuerdo con éstos últimos, esta «aprobación de principio» de revisión conllevaría la aprobación de un proyecto o proposición de ley articulado que después debería ser ratificado de nuevo por las nuevas Cortes antes de proceder a su enmienda (artículos 147.1 RdC y $159 \mathrm{RdS}$ ).Sin embrago, como expuesto por De Vega García, lo único que deben aprobar las Cortes por mayoría de dos tercios antes de procederse a su disolución es «la conveniencia o la necesidad de la reforma», no un texto articulado de la reforma constitucional. Véase De Vega García, P. (2011). La reforma constitucional y la problemática del poder constituyente, p. 146. Pérez Royo ha profundizado en dicha idea señalando la regulación de los reglamentos de las cámaras carece de sentido por diferentes motivos. En primer lugar, porque «con el fin de la legislatura decaen todos los trabajos pendientes y, en consecuencia, la nueva legislatura no se ve vinculada en modo alguno por el «proyecto o proposición» aprobado «en principio» por la legislatura anterior. Lo único que cuenta es que la primera legislatura se pronunció sobre la conveniencia u oportunidad de la revisión. Pero nada más». Pero es que, además, el artículo 168.2 CE señala que las nuevas Cortes tienen que proceder a «ratificar la decisión y proceder al estudio del nuevo texto constitucional». Es decir, señala expresamente que se trata de una decisión y no de un texto articulado. Véase Pérez Royo, J. (1987). La reforma de la Constitución. Madrid: Publicaciones del Congreso de los Diputados, p. 200.

35 Recuerda García-Escudero Márquez que el artículo 168 no prevé un mecanismo que permita una conciliación de las diferencias entre el Congreso y el Senado. Esta circunstancia es más que probable que pueda producirse debido a la introducción de enmiendas en el Senado. Como bien señala la citada autora, para dar solución a dicha cuestión hay que proceder a la aprobación del Reglamento de las Cortes Generales previsto en el artículo 72.2 de la Constitución. En su defecto, los reglamentos de las Cámaras o un acuerdo adoptado por las Mesas del Congreso y el Senado en reunión conjunta podrían solventar dicha eventualidad. En el caso de nuestro último proceso constituyente, si bien la creación de una Comisión Mixta Congreso-Senado estaba prevista en el artículo 3.2 de la Ley para la reforma política, éste extremo fue únicamente desarrollado en los artículos 125 y siguientes del Reglamento Provisional del Senado, no haciéndose mención alguna en el Reglamento Provisional del Congreso. Tal precedente lleva a pensar que no sería siquiera necesaria una reforma de ambos Reglamentos, sino que bastaría con que se reformara uno de ellos, aunque sería deseable que se introdujera dicha posibilidad en los reglamentos de ambas Cámaras. Véase García-Escudero Márquez, P. (2008). El procedimiento agravado de reforma de la Constitución de 1978. Revista de Derecho Político, 71-72, p. 188.

36 García Roca, J. (Ed.). (2014). El procedimiento de reforma constitucional. Pamplona: Aranzadi. 


\subsection{Probibición del uso del procedimiento de urgencia y lectura única en el caso de reforma a través del artículo 167}

Las dos reformas de la Constitución que hasta entonces han tenido lugar se han tramitado haciendo uso del procedimiento de urgencia y lectura única. No creo necesario desarrollar extensivamente la idea de que una reforma constitucional requiere de un debate en profundidad entre las diferentes fuerzas políticas, lo que demanda de su tratamiento en Comisión y de un amplio debate social dando la máxima publicidad a la propuesta. A ello han dedicado una reflexión en profundidad, a la que me sumo, autores como Aranda Álvarez ${ }^{37}$ y Ridaura Martínez ${ }^{38}$. Conviene entonces proceder a establecer reglamentariamente la prohibición del uso del procedimiento de urgencia y lectura única para que una situación de estas características no vuelva a repetirse y dé cabida al Tribunal Constitucional, véase al respecto el Auto 9/2012 de 13 enero, para argumentar que en los Reglamentos de las Cámaras no se establecen limitaciones de acuerdo con las cuales la reforma constitucional no se pueda producir haciendo uso de tales especialidades procedimentales.

\subsection{La introducción de mecanismos participativos y de transparencia en el caso de reforma a través del artículo 168}

Con el objeto de plasmar en mejor medida la pluralidad de la Cámara en la redacción del anteproyecto de Constitución, fomentar la transparencia del proceso, dar la oportunidad de participación a los ciudadanos y facilitar el contacto entre constituyentes y ciudadanía, conviene que el trabajo se realice en varias comisiones temáticas especializadas y no se encargue de ello una ponencia constitucional. Aunque se permita, como en el caso de nuestro último proceso constituyente, en segunda lectura, el envío de propuestas ciudadanas a la ponencia, el trabajo a puerta cerrada impide conocer hasta qué punto se han tomado éstas en consideración. Así, siguiendo el modelo islandés, debe establecerse que el proyecto de Constitución se irá publicando periódicamente, mientras se vaya debatiendo. Ello permite que la ciudadanía pueda controlar en todo momento cómo se desarrolla el proceso de redacción, cuáles son las posturas que van adoptando sus representantes y que la interacción entre constituyentes y ciudadanos sea constante. La publicación periódica del borrador en los medios de comunicación, que, como en Islandia, puede fijarse semanalmente, promueve el debate social, el interés en el proceso y el conocimiento de la futura Constitución ${ }^{39}$.

37 Aranda Álvarez, E. (2012). La «sustancialidad» del procedimiento de reforma constitucional. Teoria y Realidad Constitucional, 29, 389-408.

38 Ridaura Martínez, M. J. (2012). La reforma del artículo 135 de la constitución española ¿Pueden los mercados quebrar el consenso constitucional? Teoria y Realidad Constitucional, 29, 237-260.

39 González Cadenas, D. (2018). Democracia y procesos constituyentes. Un análisis jurídico-político. Valencia: Tirant lo Blanch, p. 144; Landemore, H. (2015). Inclusive Constitution-Making: The Icelandic Experiment. The Journal of Political Philosophy, 23(2), p. 174.

(C) UNED. Revista de Derecho Político 
Por lo que respecta a la participación ciudadana, conviene establecer mecanismos que garanticen que no se produzca en el vacío. La «participación sin poder» ${ }^{40}$ tiene como efecto adverso la disminución de sensación de pertenencia del texto en la ciudadanía ${ }^{41}$. En este sentido, son dos las grandes líneas que deben seguirse. En primer lugar, al margen de las propuestas que puedan recabar los constituyentes en diferentes encuentros públicos, debe pensarse una forma de recolección y sistematización de las propuestas ciudadanas, agrupándolas en grandes tipos de sugerencias para que éstas puedan ser contabilizadas y, posteriormente, aquellas que tengan un especial interés o un gran número de apoyos, sean obligatoriamente debatidas por el Pleno o la comisión correspondiente. Los técnicos que realicen dicha labor deberán además preparar un informe detallando sus trabajos, en paralelo al que puedan realizar observatorios ciudadanos. Lógicamente, la decisión sobre la incorporación de propuestas ciudadanas al texto debe recaer sobre los representantes (incluso un elevado número de peticionarios no pueden decidir por el conjunto de los ciudadanos), pero éstos se verán en la obligación de generar un debate en torno a cuestiones que no formen parte de la agenda de los grupos políticos.

En segundo lugar, podría incorporarse la posibilidad de que un porcentaje de ciudadanos o de representantes puedan plantear textos de artículos alternativos a los aprobados para ser sometidos a la consideración de sus conciudadanos en el referéndum de ratificación del texto. En este caso, a diferencia del anterior, al tener oportunidad de expresarse directamente el conjunto de la ciudadanía, la decisión final no recae sobre los representantes. Este mecanismo permite que determinadas cuestiones consideradas de suma importancia por la ciudadanía formen parte del debate constitucional en la sociedad. Asimismo, a diferencia de los referéndums de ratificación constitucional que se han dado en la práctica totalidad de los casos desde el referéndum francés de 1793, se permite a la ciudadanía decidir sobre cuestiones aisladas en lugar de verse obligados a votar en bloque el texto constitucional ${ }^{42}$.

Ello requeriría la reforma del artículo séptimo de la Ley Orgánica 2/1980 sobre regulación de las distintas modalidades de referéndum. De acuerdo con el mismo, únicamente se somete a votación el proyecto de reforma aprobado por las Cortes Generales. Cabría entonces especificar que, en caso de que se activara el mecanismo por parte del porcentaje requerido de ciudadanos o representantes, se someterá también a referéndum los artículos alternativos planteados, colocando en paralelo en la

${ }^{40}$ Banks, A. (2008). Expanding participation in constitution making: challenges and opportunities. William E Mary Law Review, 49(4), 1045.

${ }^{41}$ Haysom, N. (2003). Nation-building and constitution-making in divided societies. En R. Blindenbacher \& A. Koller (Eds.), Federalism in a Changing World: Learning from Each Other (pp. 216239). Montreal: McGill-Queen's University Press, p. 231.

${ }^{42}$ Viciano Pastor, R. (2012). La activación política del poder constituyente en España y sus cauces jurídicos. En R. Viciano Pastor (Ed.), Por una Asamblea Constituyente (pp. 130-146). Madrid: Sequitur, p. 145. 
papeleta las dos redacciones del texto: la aprobada por las Cortes y la propuesta por la ciudadanía o grupos minoritarios de representantes ${ }^{43}$.

En otro orden de las cosas, convendría introducir no sólo un límite máximo temporal para el desarrollo de los trabajos relativos a la reforma de la Constitución, sino también un mecanismo coercitivo que penalice de alguna forma el incumplimiento de los tiempos acordados. Es posible que, debido a la fragmentación política de las cámaras, se produzca una situación de bloqueo que impida que la agenda reformista pueda avanzar. Ahora bien, la experiencia comparada ha demostrado que en muchas ocasiones el tiempo inicialmente establecido tiende a dilatarse. Por ello, es necesario establecer, tal y como se determinó en la Petite Constitution que reguló el proceso constituyente francés de 1945-1946, que en caso de que el órgano constituyente ${ }^{44}$ se extienda en sus trabajos más de lo reglado, se procederá automáticamente a disolverlo y a convocar nuevas elecciones. Esa es, posiblemente, la única forma de que los constituyentes electos terminen sus trabajos a tiempo ${ }^{45}$.

${ }^{43}$ Ha de tenerse presente, no obstante, que dicho mecanismo podría ser considerado inconstitucional al entenderse que es una forma subrepticia de iniciativa popular de reforma y que se estaría alterando el papel preponderante que los artículos 167 y 168 otorgan a las Cámaras. En sentido contrario, podría argumentarse que el artículo 166 determina los sujetos legitimados para iniciar el proceso, pero nada dice acerca de la posibilidad de participación de los ciudadanos una vez iniciando el mismo. Es más, como ya se ha subrayado, en el propio proceso constituyente de 1977-1978, se enviaron propuestas ciudadanas a la ponencia, con lo que la vía para establecer un mecanismo de interacción directo entre representantes y representados queda también abierta por los propios acontecimientos del último proceso constituyente. En cualquier caso, de considerarse inconstitucional este artículo, siempre quedaría abierta la vía para que se reformara el procedimiento de reforma dejando claramente abierta dicha posibilidad.

${ }_{44}$ Conviene aquí hacer una breve aclaración terminológica. Por órgano constituyente me refiero genéricamente al órgano encargado de redactar y aprobar un nuevo texto constitucional. Esto es, al órgano en el que está representado el poder constituyente, esto es, el poder del pueblo de dotarse o modificar una Constitución, y que tiene por finalidad debatir, redactar y aprobar una Constitución. Por órgano constituido, por el contrario, me refiero al órgano legislativo ordinario. A juicio de Arato, conviene diferenciar entre convención constitucional (caso de la Convención de Filadelfia de 1787 o del órgano encargado de la redacción de la Constitución de Bonn de 1949), asamblea constituyente soberana (caso, por ejemplo, de la Convención de Pensilvania de 1776, la Asamblea Constituyente francesa de 1789-1791 o la Asamblea Constituyente de Weimar de 1918-1919) y legislatura normal (caso del España en 1977-1978 o de las repúblicas checa y eslovaca en 1992). No obstante, aquí he optado, para no complejizar la cuestión, por utilizar únicamente el referido concepto. Véase al respect Arato, A. (1995). Forms of constitution making and theories of democracy, Cardozo Law Review, 17: 197.

45 Como en el anterior supuesto, aquí también podría considerarse inconstitucional una reforma de los reglamentos de las Cámaras en el sentido señalado. Esto es, podría considerarse que los supuestos de disolución de las Cortes ya están previstos en el texto constitucional (artículos 99.5, 115 y 168.1) y que, por lo tanto, no sería posible añadir uno extraordinario sin proceder a la reforma de la propia Constitución. Desde mi punto de vista, la Constitución no delimita en forma expresa como supuestos únicos de disolución de las cámaras a los citados, por lo que perfectamente podrían añadirse otros supuestos a través de los reglamentos de las cámaras. Dicho lo cual, de nuevo, en caso de que esta cuestión pudiera causar recelos de inconstitucionalidad entre alguno de los sujetos legitimados para plantear uno recurso en tal sentido, y de que el Tribunal Constitucional hiciera una lectura restrictiva de lo determinada en el texto, esta propuesta debería añadirse como propuesta de reforma del artículo 168 de la Constitución.

(C) UNED. Revista de Derecho Politico

N. ${ }^{\circ} 108$, mayo-agosto 2020, págs. 247-281 
En relación directa con la finalización de los trabajos de reforma constitucional, conviene regular el régimen de transición una vez se ha procedido a la aprobación del texto. En este sentido, la forma en que se operó en nuestro último proceso constituyente es ejemplar. Esto es, una vez entrado en vigor el nuevo texto, debe decretarse inmediatamente la disolución de las cámaras y la convocatoria de elecciones, las cuales deberán tener lugar en el menor periodo de tiempo. De esta forma, se evita que el órgano constituyente continúe con sus trabajos una vez aprobada la Constitución otorgándose funciones legislativas y se facilita la implementación de las nuevas instituciones y mecanismos constitucionales ${ }^{46}$. La Constitución española, en su disposición transitoria octava, dejó abierta la posibilidad de que las Cortes terminasen su mandato, siempre y cuando el presidente dimitiese y se procediese a su investidura conforme a lo establecido en el texto recientemente aprobado. Los artículos 167 y 168 y los reglamentos de las cámaras no hacen referencia alguna a la cuestión, por lo que es necesario colmar este vacío en el sentido señalado.

Por último, con el objeto de acercar el nuevo texto constitucional a la juventud y fomentar la participación política, debería pensarse en la posibilidad de ampliar la posible participación a los mayores de dieciséis años. Sin entrar aquí en el debate doctrinal al respecto ${ }^{47}$, es importante entrar a considerar dicha opción, máxime cuando de acuerdo al nuevo reglamento de la Iniciativa Ciudadana Europea se anima a los Estados miembros en su artículo 2 a disminuir la edad para poder apoyar una iniciativa a los dieciséis años. Como bien ha señalado Giménez Gluck, esta reforma puede operarse sin una reforma de la Constitución, debiendo procederse a reformar la Ley Electoral ${ }^{48}$.

\section{REPLANTEAMIENTO POR ARTÍCULOS DEL PROCEDIMIENTO DE REFORMA ESTABLECIDO EN LA CONSTITUCIÓN}

No entraré aquí en el debate acerca de la posibilidad de reformar el procedimiento de reforma constitucional a través del artículo del 167 o la necesidad de hacerlo a través del propio procedimiento agravado. Como es sabido, desde un prisma teórico constitucional, el debate acerca de las vías por las cuales se puede proceder a la reforma del procedimiento de reforma fue célebremente planteado por Ross ${ }^{49}$, lo que le valió la respuesta de, entre otros, $\mathrm{Hart}^{50}$. El análisis concreto positivo desde el caso español

${ }^{46}$ Fernández Segado, F. (1996). Disposición Transitoria octava. Cortes constituyentes y gobierno tras la promulgacion de la Constitucion. En Ó. Alzaga Villaamil (Ed.), Comentarios a la Constitucion Española de 1978. Tomo XII (pp. 717-744). Madrid: Cortes Generales, p. 741; Santaolalla López, F. (1985). Disposición transitoria octava. En F. Garrido Falla (Ed.), Comentarios a la Constitución (pp. 24532459). Madrid: Civitas, p. 741.

47 Presno Linera, M. (2011). El derecho de voto: un derecho político fundamental, p. 34.

48 Giménez Gluck, D. (2012). El derecho de sufragio activo y la mayoría de edad. Teoría y derecho: revista de pensamiento jurídico, (12), 190-206.

49 Ross, A. (1963). Sobre el Derecho y la Justicia. Buenos Aires: Eudeba.

${ }^{50}$ Hart, H. L. A. (1983). Essays in Jurisprudence and Philosophy. New York: Oxford University Press. 
ha contando con posturas divergentes. Por un lado, una parte minoritaria de la doctrina señala que el Título $\mathrm{X}$ establece claramente cuáles son los preceptos que son susceptibles de reforma por la vía simplificada y cuáles lo son por la vía agravada. Entre éstos últimos no se encuentran los propios procedimientos de reforma, por lo que siendo meridianamente claro el texto es obvio que no cabría realizar elucubraciones de carácter teórico que contradijeran su propia letra ${ }^{51}$. Por otro lado, hay quien entiende que, a pesar de que el artículo 168 no señala entre las materias que requieren una especial protección el propio Título X, se estaría produciendo un fraude a la Constitución en caso de proceder a su reforma por la vía del $167^{52}$. Se estaría, en otras palabras, otorgando al poder de reforma funciones constituyentes ${ }^{53}$. Las disposiciones especialmente protegidas por el 168 podrían, por lo tanto, ser reformadas obviándose los requisitos agravados de tal artículo, cuestión que cabe evitar delimitando que la reforma del 168 se pueda únicamente producir a través de sí mismo ${ }^{54}$. En suma, como lo resume García-Escudero Márquez, mientras que el primer enfoque es estrictamente jurídico, el segundo añade elementos metajurídicos que van más allá de una lectura literal de la Constitución 55 .

\subsection{Introducción de la iniciativa ciudadana constitucional y constituyente}

La primera cuestión a abordar, siguiendo el orden del articulado del título X, es acerca de los sujetos legitimados para plantear una reforma constitucional. De acuerdo con la Comisión de Venecia ${ }^{56}$, las constituciones excesivamente rígidas, como sería

51 Viciano Pastor, R. (2012). La activación política del poder constituyente en España y sus cauces jurídicos. En R. Viciano Pastor (Ed.), Por una Asamblea Constituyente (pp. 130-146). Madrid: Sequitur, p. 142; Laporta San Miguel, F. J. (2004). Las dos vías para la reforma de la Constitución. Claves de razón práctica, 145, 14-23.

52 Belda Pérez-Pedrero, E. (2012). Los límites a la reforma constitucional ante propuestas más propias de una revolución. Teoria y Realidad Constitucional, 29, p. 286.

53 Moreso, J. J. (1991). Disposiciones de reforma constitucional. Doxa: Cuadernos de filosofía del derecho, 10, p. 218; De Vega García, P. (2011). La reforma constitucional y la problemática del poder constituyente, p. 277.

54 Aláez Corral, B. (2018). El procedimiento de reforma constitucional cuarenta años después. En R. Punset Blanco, L. Álvarez Álvarez, \& J. M. Roca Martínez (Eds.), Cuatro decadas de una Constitución normativa (1978-2018): Estudios sobre el desarrollo de la Constitución Española (pp. 639-667). Madrid, p. 657; Contreras Casado, M. (2017). ¿Reformar la Reforma? Un balance crítico de los procedimientos de reforma constitucional en la Constitución española. En J. Cano Bueso \& R. Escudero Rodríguez (Eds.), Estudios en Homenaje a Alfonso Guerra. La Constitución a Examen: la Reforma de la Constitución en España (pp. 59-74). Valencia: Tirant lo Blanch, p. 72; De Otto y Pardo, I. (2008). Derecho Constitucional. Sistema de fuentes. Barcelona: Ariel, p. 67.

55 García-Escudero Márquez, P. (2008). El procedimiento agravado de reforma de la Constitución de 1978. Revista de Derecho Político, (71-72), p. 192.

${ }^{56}$ Haller, G., Sejersted, F., Tuori, K., \& Velaers, J. (2010). Report on constitutional amendment. Estrasburgo, p. 4.

(C) UNED. Revista de Derecho Politico

N. ${ }^{\circ} 108$, mayo-agosto 2020, págs. 247-281 
el caso de la española ${ }^{57}$, bloquean el cambio constitucional impidiendo el desarrollo democrático e inhabilitando a la eventual mayoría que apueste por la reforma. Como lo expresa De Cabo Martín, la reforma es «la válvula de seguridad de todo el sistema» ${ }^{58}$. En un contexto de deslegitimación del sistema político y constitucional, si dicho procedimiento no puede activarse, se crea el caldo de cultivo para que la salida se produzca fuera de los cauces establecidos, propiciándose así la ruptura del hilo constitucional ante la imposibilidad o excesiva dificultad de poner en marcha el procedimiento de reforma ${ }^{59}$. Por ello, y ante la posibilidad de que se produzcan fuertes situaciones de inestabilidad social, «es aconsejable diseñar las constituciones liberales y democráticas de tal forma que dejen abierta una vía para llevar a cabo la transformación constitucional ${ }^{60}$. En este sentido, convendría regular mecanismos que permitan a la ciudadanía plantear directamente la reforma de la Constitución evitando así el salto al vacío que supone su transformación fuera de los cauces establecidos. Parece además razonable afirmar que si la Constitución es un instrumento de garantía de los ciudadanos frente a los posibles abusos del poder político, resulta extraño que estén legitimados para plantear su reforma los limitados por la Constitución y no los limitantes. De esta forma, algunos sistemas constitucionales han añadido mecanismos que posibilitan a los ciudadanos plantear reformas a la norma superior de su ordenamiento jurídico ${ }^{61}$.

En España, el artículo 166 CE establece que únicamente tienen legitimidad para iniciar el proceso de reforma constitucional Gobierno, Congreso, Senado y Asambleas de las Comunidades Autónomas. Esta decisión, como se ha recordado en varias ocasiones, no estuvo exenta de polémica durante los debates constituyentes ${ }^{62}$. Efectiva-

57 De Vega García, P. (2011). La reforma constitucional y la problemática del poder constituyente, p. 148; Jiménez Campo, J. (1980). Algunos problemas de interpretación en torno al Título X de la Constitución. Revista de derecho político, (7), p. 84.

58 De Cabo Martín, C. (2009). Dialéctica del sujeto, dialéctica de la Constitución. Madrid: Trotta, p. 53.

59 Colón-Ríos, J. I. (2011). Carl Schmitt and constituent power in Latin American courts: The cases of Venezuela and Colombia. Constellations, 18(3), p. 378.

${ }^{60}$ Holmes, S., \& Sunstein, C. (1995). The politics of constitutional revision in eastern Europe. En S. Levison (Ed.), Responding to imperfection: The theory and practice of constitutional amendment (pp. 275-306). Princeton: Princeton University Press, p. 277.

61 Es el caso, por ejemplo, del instituto de la iniciativa popular, regulado en los artículos 138 y 139 de la Constitución suiza y los artículos 68 y siguientes de la Ley federal suiza sobre los derechos políticos. Véase al respecto Sánchez Ferriz, R. (2017). Formas y niveles territoriales de la iniciativa popular y del referéndum en el ordenamiento suizo. Revista de derecho constitucional europeo, 28; Sáenz Royo, E. (2016b). La regulación y la práctica del referéndum en Suiza: Un análisis desde las críticas a la institución del referéndum. Revista de Estudios Políticos, 171, 71-104. Pueden consultarse asimsimo los variados mecanismos de iniciativa ciudadana en la reforma constitucional parcial y total regulados en diversas constituciones estatales de Estados Unidos. Véase Dinan, J. (2016). State Constitutional Initiative Processes and Governance in the Twenty-First Century. Chapman Law Review, 19(1), 61-108.

62 Presno Linera, M. (2014). La democracia participativa como instrumento de impulso, deliberación y control. Ponencia presentada en Salamanca el XII Congreso de la Asociación de Constitucionalistas de España el 3 de abril de 2014, p. 14. 
mente, en el Anteproyecto de Constitución no estaba prevista la exclusión de la ciudadanía. Una enmienda de UCD, que apoyaron prácticamente todos los grupos, con la destacada excepción de Alianza Popular, estableció tal impedimento. La inmensa mayoría de los diputados percibieron que España seguía siendo un país sociológicamente franquista y que la inclusión de mecanismos de democracia directa podría ser beneficiosa para introducir determinados correctivos conservadores. Esa apreciación definió su posición política más allá de cualquier otra consideración teórica constitucional $^{63}$. Dicha percepción, no obstante, se demostró errónea tras el abrumador triunfo del PSOE del 1982, demostrándose que España era ya por aquel entonces un país mayoritariamente alejado de los valores característicos de la dictadura.

Destacados representantes de la doctrina española se adscribieron a uno y otro punto de vista. En minoría, Pérez Royo defendió las cautelas con las que actuó el constituyente $^{64}$, mientras que una mayoría de autores, entre ellos De Vega García, señalaron la conveniencia de introducir la iniciativa popular de reforma constitucio$\mathrm{nal}^{65}$. En los últimos años se han seguido reproduciendo el mismo debate con idéntico juego de mayorías dentro de la doctrina. Con alguna excepción ${ }^{66}$, la mayoría de la doctrina sigue posicionándose a favor de esta última postura ${ }^{67}$. No cabe tener reticencias ante la partipación popular en la materia, subraya Contreras Casado, cuando la decisión última sobre la iniciativa de reforma la seguiría teniendo el Parlamento ${ }^{68}$. Desarrollando dicho punto de vista, la Junta General del Principado de Asturias

${ }^{63}$ Illueca Ballester, J. E. (2018). La participación política directa en el proceso constituyente español de 1977-1978. Historia Constitucional, 19, 17-45; Sánchez Ferriz, R. (2017). Reflexiones sobre una eventual reforma constitucional de los institutos de democracia directa y semidirecta. Revista de Derecho Político, 100, 513-540.

${ }^{64}$ Pérez Royo, J. (1987). La reforma de la Constitución. Madrid: Publicaciones del Congreso de los Diputados, p. 143.

${ }_{65}$ De Vega García, P. (2011). La reforma constitucional y la problemática del poder constituyente, p. 134.

66 Vera Santos, J. M. (2016). La reforma del procedimiento de refoma constitucional en España. Revista de Derecho Politico, 96, p. 20.

${ }^{67}$ Aláez Corral señala que «ello mejoraría la correlación entre democracia representativa y democracia participativa en una madura sociedad democrática como la española, permitiendo a la ciudadanía tomar conciencia de que en el pueblo reside el poder constituyente y no resulta preciso acudir a mecanismos ajenos al procedimiento de reforma constitucional, como un espurio proceso constituyente, para su ejercicio». Véase Aláez Corral, B. (2018). El procedimiento de reforma constitucional cuarenta años después. En R. Punset Blanco, L. Álvarez Álvarez, \& J. M. Roca Martínez (Eds.), Cuatro decadas de una Constitución normativa (1978-2018): Estudios sobre el desarrollo de la Constitución Española (pp. 639667). Madrid, p. 651. Díaz Revorio defiende que, si bien podría haber sido comprensible durante la transición el sostenimiento de la postura mayoritaria en las Cortes Constituyentes, hoy día no cabe tener dichos recelos hacia la expresión popular en la materia. Véase Díaz Revorio, F. J. (2018). Democracia, representación y participación ciudadadana, a la búsqueda de un equilibrio que la Constitución no logró. Revista de Derecho Político, 101, p. 267.

${ }^{68}$ Contreras Casado, M. (2017). ¿Reformar la Reforma? Un balance crítico de los procedimientos de reforma constitucional en la Constitución española. En J. Cano Bueso \& R. Escudero Rodríguez (Eds.), Estudios en Homenaje a Alfonso Guerra. La Constitución a Examen: la Reforma de la Constitución en España (pp. 59-74). Valencia: Tirant lo Blanch, p. 63.

(C) UNED. Revista de Derecho Politico

N. ${ }^{\circ} 108$, mayo-agosto 2020, págs. 247-281 
aprobó en 2014 una propuesta de reforma constitucional, promovida a su vez por un grupo de ciudadanos, por la que se propone modificar los artículos 87.3, 92 y 166 de la Constitución de tal manera que la ciudadanía esté legitimada para plantear la iniciativa de reforma parcial y total constitucional ${ }^{69}$.

El problema de estas propuestas es que asumen la limitada lógica de la actual regulación constitucional de la iniciativa legislativa popular ${ }^{70}$. De acuerdo con ésta, efectivamente, la decisión última recae sobre el Congreso de los Diputados, el cual tiene la capacidad de decidir si admite a trámite dicha iniciativa y, en su caso, enmendarla a voluntad. Los modelos de iniciativa popular como el español, replicados en sus líneas generales en otros Estados miembros de la Unión Europea (Austria ${ }^{71}$, Eslovaquia $^{72}$, Eslovenia ${ }^{73}$, Italia ${ }^{74}$, Lituania $^{75}$, Polonia $^{76}$, Portugal $^{77}$ y Rumanía ${ }^{78}$ ) y en la propia Iniciativa Ciudadana Europea, son modelos de iniciativa de agenda o iniciativa popular indirecta que han tenido escasa repercusión en la práctica ${ }^{79}$. Por el contrario,

${ }^{69}$ La proposición de reforma que se realizó es relación con la iniciativa de reforma constitucional la siguiente: «Modificación del artículo 87.3 de la Constitución que quedará redactado como sigue: 3 . Una Ley orgánica regulará las formas de ejercicio y requisitos de la iniciativa popular para la presentación de proposiciones de Ley. En todo caso se exigirán no menos de 500.000 firmas acreditadas. Artículo 166: La iniciativa de reforma constitucional se ejercerá en los términos previstos en el artículo 87». A día de hoy, dicha proposición sigue sin ser debatida en el Congreso, lo que ha llevado, a Balaguer Callejón y Trujillo Pérez, quienes comparten la necesidad de introducir de la iniciativa popular de reforma constitucional, a señalar que debería también establecerse que en caso de que la proposición parta de la Asamblea de una Comunidad Autónoma se produzca la defensa en el Pleno del Congreso de la misma en un plazo máximo de seis meses. Y, en el caso de que se trate de una iniciativa popular de reforma constitucional, la proposición sea incluida en el orden del día del Pleno en el plazo máximo de seis meses para su toma en consideración. Véase Balaguer Callejón, M. L., \& Trujillo Pérez, A. J. (2018). Título X. De la reforma constitucional. En Y. Gómez Sánchez (Ed.), Estudios sobre la reforma de la Constitución de 1978 en su Cuarenta Aniversario (pp. 427-440). Pamplona: Aranzadi, p. 431. Desde mi punto de vista, de seguirse por esta línea, podría resultar conveniente, como está establecido en el artículo 24 de las Reglas de Procedimiento del Consejo Nacional de Austria, que las iniciativas populares tengan prioridad sobre cualquier otro asunto o, por lo menos, se establezca un plazo más breve para ser debatidas.

70 Sáenz Royo, E. (2016). La regulación del referendo en el derecho comparado: Aportaciones para el debate en España. Revista Española de Derecho Constitucional, 108, p. 149. Para un repaso histórico a la evolución del instituto puede consultarse Biglino Campos, P. (1987). La iniciativa legislativa popular en el ordenamiento jurídico estatal. Revista Española de Derecho Constitucional, 19, 75-130.

71 Constitución de Austria, artículo 41.

72 Constitución de Eslovaquia, artículo 95.

73 Constitución de Eslovenia, artículo 88.

74 Constitución de Italia, artículo 71.

75 Constitución de Lituania, artículo 68.

76 Constitución de Polonia, artículo 118.

77 Constitución de Portugal, artículo 167.

78 Constitución de Rumanía, artículo 74.

79 Fernández Le Gal, A. (2018). La contribución de la iniciativa ciudadana europea a la vida democrática de la Unión. Revista General de Derecho Constitucional, 26, 1-44; Vázquez Rodríguez, B. (2017). La Iniciativa Ciudadana Europea, un instrumento democrático en progresiva consolidación. Revista General de Derecho Europeo, 43, 153-200; Báez Lechuga, I. (2016). Análisis jurídico-político de la Iniciativa Ciudadana Europea en el contexto de un equilibrio institucional complejo: posibles efectos dinamizadores 
resulta más coherente con el principio democrático el modelo suizo, el de Letonia ${ }^{80}$, y el de algunos estados de EEUU, de iniciativa popular directa, de acuerdo con el cual el legislativo no está capacitado para modificar la voluntad de los impulsores de la iniciativa de reforma constitucional y ésta debe ser sometida a la directa consideración de la ciudadanía ${ }^{81}$.

de la democracia a partir de la introducción de la iniciativa ciudadana en la Unión Europea. Madrid: Agencia Estatal Boletín Oficial del Estado, p. 283.

${ }^{80}$ Constitución de Letonia, artículo 78. La Constitución de Hungría en su artículo 8 establece también un modelo de iniciativa popular, pero la iniciativa popular de reforma constitucional no está permitida.

${ }^{81}$ El debate en torno a la posible contradicción entre la posibilidad de introducción de mecanismos de democracia directa y el principio de democracia representativa, establecido en nuestro texto constitucional en el artículo 1.3, remite a un debate ciertamente interesante que ha sido abordado en forma extensa por la doctrina y la jurisprudencia estadounidense debido a que el artículo IV, sección 4 de la Constitución federal establece la cláusula de garantía (guarantee clause), de acuerdo con la cual todos los Estados Unidos deben garantizar a todo Estado de la Unión una forma de gobierno republicano. Para un planteamiento general del debate, puede consultarse, por todos, Baude, P. L. (1998) A Comment on the Evolution of Direct Democracy in Western State Constitutions, New Mexico Law Review, 28, 343353. Una corriente doctrinal notable considera que la intención de los padres fundadores era establecer una forma de gobierno representativa y, por lo tanto, la introducción de mecanismos de democracia directa en las constituciones y leyes de múltiples estados debe limitarse o tratarse diferenciadamente, ya sea mediante la acción de los tribunales o mediante la introducción de legislación a nivel federal, cuando no directamente impedirse. Al respecto véase Eule, J. N. (1990) Judicial Review of Direct Democracy, Yale Law Journal, 99(7), 1503-1590. Sin embargo, el Tribunal Supremo federal nunca ha encontrado contradictoria dicha garantía con el ejercicio estatal de diferentes formas de democracia directa. Defendiendo la jurisprudencia del Tribunal Supremo que ha venido señalando que la aplicación de la guarantee clause por lo que respecta a la forma republicana de Gobierno es acertada, puede consultarse el extenso estudio de Williams, R. C. (2018) The «Guarantee» Clause, Harvard Law Review, 132, 604-688. Para el caso concreto español, si bien es cierto que el artículo 1.3 determina que la forma de Gobierno en España es la monarquía parlamentaria, ello no supone contradicción alguna con la introducción de mecanismos de democracia directa, siendo estos un complemento a la democracia representativa, no una negación de la misma. Así, de hecho, lo subraya el propio texto constitucional en el artículo 9.2 y, en forma más clara, en el artículo 23. La redacción del artículo 23 es claramente deudora de la redacción del artículo 21.1 de la Declaración Universal de Derechos Humanos y del artículo 25 del Pacto Internacional de Derechos Civiles y Políticos. En su observación general número 25, el Comité de Derechos Humanos de Naciones Unidas ha reafirmado la perspectiva aquí señalada y, al respecto, puede consultarse el caso Mi'kmaq Society v. Canada (C. No 205/1986). Es igualmente notable, como se recuerda en Viciano Pastor R. y González Cadenas D. (2015). Derecho a Participar Directamente o Mediante Representantes En El Gobierno Del Propio País. En Monereo Pérez, J.L. (ed), El sistema universal de los derechos humanos. Madrid: Comares, que el sentido de los propios redactores de la DUDH, especialmente el representante francés, René Cassin, fue el de incluir la participación directa de los ciudadanos como forma complementaria a la indirecta. El modelo de iniciativa popular ha demostrado, en otro orden de las cosas, mayor efectividad que el modelo de iniciativa de agenda. De acuerdo con los datos facilitados por la Cancillería Federal suiza, a fecha de 15 de marzo de 2019 y desde 1891, se han impulsado 466 iniciativas. De estas, el pueblo ha podido expresarse directamente en 210 casos, aceptando 22 iniciativas. Desde que se introdujo en diferentes constituciones estatales el mecanismo de iniciativa popular de reforma constitucional hasta el año 2014, se sometieron a consideración de los ciudadanos 1965 propuestas. Véase Dinan, J. (2016). State Constitutional Initiative Processes and Governance in the

(C) UNED. Revista de Derecho Político

N. ${ }^{\circ} 108$, mayo-agosto 2020, págs. 247-281 
En línea con ello y experiencias como la francesa de $1945^{82}$, Viciano Pastor ha planteado que, en el caso de una reforma total de la Constitución, deba plantearse a la ciudadanía la conveniencia de la apertura del proceso mediante referéndum convocado por el presidente del Gobierno, un número representativo de miembros de las Cortes Generales o de ciudadanos ${ }^{83}$. En dicho referéndum se preguntaría separadamente, por un lado, acerca de la apertura de un proceso constituyente y, por otro lado, la reglamentación del proceso electoral y el funcionamiento y funciones del órgano constituyente. Este referéndum de apertura permite comprobar si los ciudadanos desean iniciar el siempre espinoso camino de un proceso de reforma total de la Constitución y confiere mayor legitimidad y seguridad jurídica al proceso. La segunda pregunta, por su parte, aporta mayor seguridad jurídica al proceso al poder conocerse de antemano las normas que lo regirán y poder ser éstas aprobadas o rechazadas por la ciudadanía. Asimismo, en tanto en cuanto es consecuencia de un acto de ratificación desempeñado por el poder constituyente, la normativa aprobada podrá servir como base de resolución de los eventuales litigios que puedan ocasionarse durante el proceso.

\subsection{Obligatoriedad de referéndum en caso de activación del procedimiento de reforma del artículo $167 \mathrm{CE}$}

Posturas muy similares a las del debate acerca de la introducción de la iniciativa popular de reforma constitucional se reprodujeron en las Cortes Constituyentes para el caso del referéndum en el supuesto de reformas parciales de la Constitución por la vía del artículo 167. Una minoría de diputados y senadores, como fue el caso de la senadora por designación real María Belén Landáburu González y el portavoz del Grupo Parlamentario de Alianza Popular, Manuel Fraga Iribarne, defendieron el referéndum obligatorio en todos los casos de reforma constitucional, mientras que una mayoría se posicionó en contra ${ }^{84}$. No obstante, a diferencia del extremo relativo a la iniciativa popular de reforma constitucional, la mayoría de la doctrina se muestra favorable a dicha limitación. Esta situación es aparentemente llamativa dada la defensa por la mayoría de la doctrina de la introducción de la iniciativa popular de reforma constitucional. Sin embargo, como hemos visto, lo que la mayoría de la doctrina

Twenty-First Century. Chapman Law Review, 19(1), 61-108 y consúltese la página web especializada en procesos electorales en los Estados Unidos, Ballotpedia: https://ballotpedia.org/Initiative_frequency_ of_constitutional_amendments_related_to_time_for_signature_collection

${ }^{82}$ Gooch, R. K. (1947). Recent constitution- making in France. The American Political Science Review, 41(3), 429-446.

83 Viciano Pastor, R. (2012). La activación política del poder constituyente en España y sus cauces jurídicos. En R. Viciano Pastor (Ed.), Por una Asamblea Constituyente (pp. 130-146). Madrid: Sequitur, p. 144.

84 Pérez Royo, J. (1987). La reforma de la Constitución. Madrid: Publicaciones del Congreso de los Diputados, p. 160. 
defiende no es un mecanismo de auténtica iniciativa popular, como el que podemos encontrar en Suiza o en algunos Estados de EEUU, sino un mecanismo de iniciativa de agenda que el legislativo puede rechazar o enmendar.

Es ciertamente preocupante que una mayoría abrumadora de la doctrina defienda que la Constitución debe tener una aprobación directa popular y, sin embargo, entienda que luego pueda ser modificada sin comprobar si dicho cambio es deseado por la ciudadanía. Desde una perspectiva más coherente con la idea de Constitución como reflejo de la voluntad popular, debería procederse a la reforma del artículo 167, de tal forma que, contrariamente a las dos reformas parciales de la Constitución que hasta el momento han tenido lugar, se introduzca la obligatoriedad de consulta a la ciudadanía. Si la Constitución es el reflejo de la voluntad del poder constituyente, cualquier alteración de la misma debe contar necesariamente con su aquiescencia ${ }^{85}$. Así se entiende en algunos de los ordenamientos constitucionales más avanzados, como es el caso del suizo (artículo 195 de la Constitución suiza), que requiere de la ratificación popular para cualquier revisión constitucional. Asimismo, en el nivel estatal en los Estados Unidos, con la única excepción del Estado de Delaware, en todos los demás casos es preceptivo el asentimiento directo de la ciudadanía ante cualquier modificación parcial del texto constitucional.

\subsection{La innecesaria determinación de sólo algunos preceptos para ser objeto de una reforma parcial por la vía del artículo 168}

La práctica totalidad de la doctrina que ha reflexionado acerca del Título $\mathrm{X}$ ha señalado la arbitrariedad en la elección de los preceptos que han de ser necesariamente objeto de reforma conforme al artículo 168 CE. Para solventar esta situación, algunos autores, es el caso de Aláez Corral, han defendido una nueva determinación de preceptos sujetos al procedimiento de reforma agravado ${ }^{86}$. Otros, como Tajadura Tejada, proponen eliminar el artículo 168 introduciendo en su lugar una serie de cláusulas de intangibilidad. El artículo 168, razona Tajadura Tejada, conlleva una dificultad tal para su activación que impide o dificulta innecesariamente las posibilidades de que se lleven a cabo algunas reformas constitucionales políticamente y jurídicamente necesarias. El artículo 167, sin embargo, sí cumpliría con el necesario equilibrio entre impedir que una mayoría coyuntural débil pueda modificar la Constitución e impedir que ésta se puede reformar. En este sentido, carecería de sentido disponer de un segundo mecanismo de reforma que es difícilmente practicable y favorece la posible destrucción total de la Constitución. Por ello, para este autor, resultaría más conve-

${ }^{85}$ Martínez Dalmau, R. (2018). Soberanía popular, poder constituyente, poder constituido. Diritto Costituzionale, 1, p. 87.

${ }^{86}$ Aláez Corral, B. (2018). El procedimiento de reforma constitucional cuarenta años después. En R. Punset Blanco, L. Álvarez Álvarez, \& J. M. Roca Martínez (Eds.), Cuatro decadas de una Constitución normativa (1978-2018): Estudios sobre el desarrollo de la Constitución Española (pp. 639-667). Madrid, p. 647.

(C) UNED. Revista de Derecho Político

267

N. ${ }^{\circ} 108$, mayo-agosto 2020, págs. 247-281 
niente la introducción de cláusulas de intangibilidad que impidan la reforma total de la Constitución y protegieran efectivamente aquellas cuestiones especialmente sensibles que constituyen el núcleo de legitimidad del Estado constitucional: el Estado de Derecho, el principio democrático y los derechos fundamentales ${ }^{87}$.

Ambas propuestas tienen como núcleo compartido el otorgamiento de una mayor importancia a una serie de preceptos sobre otros, estableciéndose así una jerarquía entre los diferentes preceptos establecidos en la Constitución. En la cúspide de la misma se encontrarían todas aquellas disposiciones para cuya reforma se requiere del procedimiento agravado o que están protegidas mediante cláusulas de intangibilidad, mientras que en un segundo plano se situarían las que pueden reformarse por la vía del procedimiento de reforma simplificado. Al margen del análisis que se pueda hacer sobre las consecuencias que conlleva el establecimiento de jerarquías internas dentro de la Constitución mediante el establecimiento de cláusulas de intangibilidad, todos los preceptos constitucionales deben tener la misma fuerza normativa, no debiendo distinguirse entre disposiciones de primera y de segunda. Si el constituyente optó por incluir un precepto determinado en la Constitución es debido a que reconocía su importancia e igual aplicabilidad, independientemente de su situación. De esta forma, ya sea mediante el establecimiento de cláusulas de intangibilidad o, como en la Constitución vigente, el especial refuerzo de determinadas disposiciones, se está generando una jerarquía interna impropia de un texto jurídico normativo. La jerarquía normativa se establece entre normas y no entre los preceptos de una norma ${ }^{88}$.

${ }_{87}$ Tajadura Tejada, J. (2016). La reforma de la Constitución (arts. 166-169). En T. Freixes Sanjúan \& J. C. Gavara de Cara (Eds.), Repensar la constitución. Ideas para una reforma de la Constitución de 1978: reforma y comunicación dialógica (pp. 257-281). Madrid: Boletín Oficial del Estado, p. 264. En similares términos véase Vera Santos, J. M. (2016). La reforma del procedimiento de refoma constitucional en España. Revista de Derecho Político, 96, p. 44.

${ }^{88}$ De acuerdo con Otto Bachof, los preceptos constitucionales protegidos por cláusulas pétreas deben ser considerados jerárquicamente superiores a los demás, por lo que podrían entonces conllevar la declaración de inconstitucionalidad de los preceptos que se les opusieran. Véase Bachof. O. (2010). ¿Normas constitucionales inconstitucionales? Lima: Palestra Editores. En España, parte de la doctrina retomó la consideración de Bachof, a pesar de la inexistencia de cláusulas pétreas en nuestra Constitución, para entrar a considerar la posibilidad de que los preceptos que determinan el procedimiento de sucesión en la Corona fueran declarados inconstitucionales al ser contradictorios con el principio de igualdad. Véase al respecto Gómez Lugo, Y. y Mellado Prado, P. (1986). En torno a la posible inconstitucionalidad del apartado primero del artículo 57 de la Constitución española de 1978. Revista de Derecho Político, 22, 175-195. Recientemente, varios órganos de control constitucional de diversos países de América Latina han utilizado los mismos argumentos acerca de la existencia una jerarquía interna entre diferentes disposiciones constitucionales para considerar que la prohibición constitucional de la reelección constitucional es inconstitucional. Puede consultarse al respecto el detallado estudio Viciano Pastor, R., \& Moreno González, G. (2018). Cuando los jueces declaran inconstitucional la Constitución: la reelección presidencial en América Latina a la luz de las últimas decisiones de las Cortes Constitucionales. Anuario Iberoamericano de Justicia Constitucional, 22, p. 188. En sentido contrario, puede argumentarse que a la obra del poder constituyente debe dotársela por igual de un mismo valor y situarse en un mismo escalafón jerárquico. La introducción de una diferenciación entre preceptos en el texto constitucional español a través del procedimiento de reforma deja la vía abierta para que el Tribunal Constitucional 
A ello ha de sumarse, además, el amplio margen de interpretación que se otorga al Tribunal Constitucional para decidir sobre cuestiones materiales. En caso de que se mantenga la actual división, siempre cabe la duda de qué hacer con aquellos preceptos que pudiendo reformarse por la vía del artículo 167, afecten directamente a disposiciones protegidas por el 168. El Tribunal Constitucional ha tenido ocasión de pronunciarse al respecto con ocasión de las dos reformas constitucionales. Por lo que respecta a la reforma del artículo 13.2 CE, el TC, en su Declaración 1/1992 de 1 de julio, asumió un criterio estrictamente formalista y no realizó consideración alguna sobre la posible afectación de dicha reforma a otras partes del articulado protegidas por el artículo 168 (FJ 6). En el caso de la reforma del artículo 135, el TC, mediante el Auto 9/2012, de 13 de enero de 2012, afirmó que no ha lugar la consideración pretendida por los recurrentes de acuerdo con la cual «el contenido de la propuesta de reforma del artículo 135 de la Constitución Española implica una modificación encubierta de su Título Preliminar y, en consecuencia, su tramitación debe seguir los trámites contemplados por el artículo $168{ }^{89}$. De acuerdo con su criterio, ateniendo a la literalidad del texto, no pueden determinase eventuales conexiones de una propuesta de reforma por la vía del 167 de un precepto que no se encuentre entre aquellas disposiciones especialmente protegidas en el artículo 168 (FJ 2) ${ }^{90}$.

pueda enteder, siguiendo la conceptualización de Pfersmann, que existe «una diferenciación jerárquica dentro del derecho Constitucional formal, considerado globalmente». Véase Pfersmann, O. (2013). Reformas constitucionales inconstitucionales: una perspectiva normativista. Revista Española de Derecho Constitucional, 99, p. 35. Así lo ha hecho, por ejemplo, una Corte Constitucional de reconocido prestigio como es la colombiana, al determinar la existencia de una diferenciación jerárquica dentro de los diferentes preceptos constitucionales y declarar la inconstitucionalidad de una reforma constitucional. Véase al respecto Zúñiga Urbina, F. y Cárcamo Tapia, R. (2015). ¿Inconstitucionalidad de normas constitucionales? Derecho Público Iberoamericano, 7, 219-237. A mi juicio, la solución que aporta para tal caso el TJUE, como se desarrolla en el apartado 4.6, es la adecuada. A esta postura se sumaría también Sabrina Ragone, quien ha argumentado con sumo rigor que el control constitucional de las reformas constitucionales debe ser únicamente formal y material en caso de existencia de un procedimiento diferenciado, como es el caso del español o el del propio TUE. Pero, en ningún caso, argumenta Ragone, debe tener potestad el órgano de control constitucional para declarar inconstitucional una reforma constitucional por violación de otro precepto constitucional. Véase Ragone, S. (2013). El control material de las reformas constitucionales en perspectiva comparada. Teoría y Realidad Constitucional, 31, 391-405.

89 Recurso de amparo 5241-2011 presentado por el grupo parlamentario Esquerra RepublicanaIzquierda Unida-Iniciativa per Catalunya.

Disponible en línea en: http://izquierda-unida.es/sites/default/files/doc/Recurso\%20de\%20 amparo\%20al\%20TC.pdf

${ }^{90}$ Por otra parte, ha de subrayarse que el TC, asumiendo el criterio de la Mesa del Congreso de los Diputados, señaló que no hay debate doctrinal al respecto del tema que nos ocupa aquí. Pues bien, Pedro de Vega, ampliamente citado por toda la doctrina que ha analizado el procedimiento de reforma constitucional y referente indiscutible en la materia, adoptó una postura contraria a la de nuestro órgano de control de constitucionalidad. Según el respetado profesor, ha de diferenciarse entre dos tipos de reformas constitucionales: las expresas, que hacen directamente referencia a aquellas materias que se pretenden reformar; y las tácitas, aquellas reformas que no especifican claramente todos aquellos preceptos que pudieran resultar afectados por la reforma. «Lo que sí que puede ocurrir en un sistema constitucional como el español, con normas de distingo rango a las que se aplican procedimientos de

(C) UNED. Revista de Derecho Politico

N. ${ }^{\circ} 108$, mayo-agosto 2020, págs. 247-281 
Para coger un poco de perspectiva sobre una cuestión tan delicada, merece la pena ver cómo ha tratado esta cuestión el Tribunal de Justicia de la Unión Europea ante la reforma de los Tratados de la Unión. Aunque obviamente el análisis del TJUE no verse sobre un texto constitucional ${ }^{91}$, se trata de una situación comparable a la que cabe prestar atención. En el caso Pringle, resuelto mediante sentencia del Pleno del TJUE el 27 de noviembre de 2012, se enjuiciaron, entre otras cuestiones, la adecuación de una reforma del TUE al procedimiento de reforma establecido en el artículo 48 del citado Tratado. En forma similar al caso español, el TUE contempla dos vías para la reforma de los Tratados. El procedimiento de revisión simplificado se diferencia del ordinario, que requiere de la convocatoria de una Convención y una Conferencia Intergubernamental, en que puede llevarse a cabo mientras afecte a materias encuadradas en la tercera parte del TFUE y que no impliquen un aumento de las competencias atribuidas a la Unión. El TJUE no se limitó a determinar que, debido a que el artículo 136 TFUE se encuadra formalmente dentro de la tercera parte del TFUE, no cabían ulteriores elucubraciones. Bien al contrario, el TJUE, en clara contradicción al proceder del TC, entró a analizar si dicha reforma afectaba materialmente a otras partes de los Tratados que requerían de la vía de reforma agravada (FFJJ 45 y ss.).

Por lo que respecta exclusivamente a la introducción de cláusulas de intangibilidad, sin entrar a debatir acerca del bloqueo de cambio de generaciones pasadas sobre las futuras que significa y la plena desconfianza en la voluntad popular y en la negación del poder constituyente que está en el trasfondo de ese tipo de argumentaciones, es importante subrayar, pese a su obviedad, que las cláusulas de intangibilidad favo-

revisión diferentes, es que, reformas producidas por el mecanismo del artículo 167, si no explicitan claramente los preceptos del texto de la Constitución que se pretenden reformar, pueden afectar a supuestos cuya vía de revisión está prevista en el artículo 168. Con lo cual, la reforma constitucional tácita se convertiría, no en un instrumento de desconstitucionalización total, como indicara Laband, pero sí en un medio indirecto a cuyo través podrían trasladarse las normas protegidas por el artículo 168 al ámbito de las normas amparadas por el artículo 167. A la vista del silencio de nuestro texto constitucional sobre esta materia, cabe sólo esperar que, en nombre de la seguridad y la claridad jurídicas, nuestro futuro legislador constituyente apele, en los supuestos que la reforma constitucional se haga necesaria, a la revisión expresa, y no a la mala técnica de la reforma constitucional tácita». De Vega García, P. (2011). La reforma constitucional y la problemática del poder constituyente, p. 162 y ss.

91 De Carreras Serra, F. (1995). Por una Constitución Europea. Revista de Estudios Políticos, 90, p. 204; Díez-Picazo Giménez, L. (1993). Reflexiones sobre la idea de Constitución Europea. Revista de Instituciones Europeas, 2, 533-562. Ha de tenerse, en cuenta, no obstante, que la mayoría de la doctrina constitucional europea sí equipara el derecho originario europeo con un modelo constitucional. En ese sentido, por ejemplo, puede consultarse: Weiler, J. (1991) The transformation of Europe, Yale Law Journal, 100(8), 2403-2483; Scarlatti, P. (2010) Democracia y teoría de la legitimación en la experiencia de la integración europea: Contribución a una crítica del constitucionalismo multinivel. Bilbao: Universidad del País Vasco; Craig, P. (2011) Constitutions, constitutionalism and the European Union, European Law Journal, 7(2), 125-150. Asimismo, el propio TJUE desde 1986 explicitó claramente en la conocida sentencia Les Verts v. European Parliament que: «En este sentido, es pertinente subrayar, en primer lugar, que la Comunidad Económica Europea es una comunidad de Derecho, en la medida en que ni sus Estados miembros ni sus instituciones pueden sustraerse al control de la conformidad de sus actos con la carta constitucional fundamental que constituye el Tratado.» 
recen la activación del poder constituyente fuera de los cauces establecidos. Si en un momento histórico dado existe una voluntad mayoritaria clara para modificar alguna de los elementos centrales de la Constitución o de reiniciar desde cero un proceso de construcción constitucional, ello va a terminar produciéndose tarde o temprano, independientemente de que se hayan introducido cláusulas de intangibilidad constitucional, independientemente de que se pretenda creer ilusoriamente que con ello los derechos fundamentales se impondrían al principio democrático, o independientemente de que se faculte al Tribunal Constitucional para controlar el contenido de la reforma antes de que se proceda a ser sometida a referéndum. Así, en lugar de presionar en favor de la vía de la ruptura del hilo constitucional, vía que es en última instancia siempre legítima ${ }^{92}$ y que podrá activarse en el caso español a través del artículo $92 \mathrm{CE}^{93}$, debe favorecerse que existan mecanismos que posibiliten cualquier cambio constitucional con la seguridad jurídica que aportan los procedimientos reglados constitucionalmente.

En suma, las dos soluciones propuestas por parte de la doctrina contienen elementos que no resultan aconsejables. Por un lado, constituir dos vías de reforma en la que se protegen determinados artículos sobre otros genera una tensión obvia que debería evitarse. Por otra parte, en caso de que se optara por la introducción de cláusulas de intangibilidad, se presenta, en similar sentido, el problema de una valoración política contra-mayoritaria del Tribunal Constitucional ${ }^{94}$, por lo que tampoco es una solución óptima al problema. Por ello, con la finalidad de evitar una determinación entre artículos que siempre resultará arbitraria, crea normas de diversa importancia jurídica en función del mecanismo por el que se debiera optar y conlleva una toma de postura del órgano de control constitucional acerca de las reformas tácitas de la Constitución que resulta sumamente discutible, debería procederse a la eliminación de la posibilidad de reforma parcial constitucional a través del artículo 168. O, por expresarlo con otra terminología, para evitar posibles tendencias hacia interpretaciones que determinen la existencia de una jerarquía intraconstitucional, parecería más adecuado, siguiendo la conceptualización de Pfersmann ${ }^{95}$, optar por un modelo de monoformismo constitucional, de tal forma que se excluya cualquier posibilidad de consideración de reformas constitucionales inconstitucionales.

92 Braver, J. (2017). Constituent Power as Extraordinary Adaptation. Disponible en SSRN: https:// ssrn.com/abstract=3022221; Tushnet, M. (2013). Constitution-making: an introduction. Texas Law Review, 91(7), p. 1989.

93 Viciano Pastor, R. (2012). La activación política del poder constituyente en España y sus cauces jurídicos. En R. Viciano Pastor (Ed.), Por una Asamblea Constituyente (pp. 130-146). Madrid: Sequitur, p. 142 .

94 Aláez Corral, B. (2018). El procedimiento de reforma constitucional cuarenta años después. En R. Punset Blanco, L. Álvarez Álvarez, \& J. M. Roca Martínez (Eds.), Cuatro decadas de una Constitución normativa (1978-2018): Estudios sobre el desarrollo de la Constitución Española (pp. 639-667). Madrid, p. 654.

95 Pfersmann, O. (2013). Reformas constitucionales inconstitucionales: una perspectiva normativista. Revista Española de Derecho Constitucional, 99, p. 35.

(C) UNED. Revista de Derecho Politico

N. ${ }^{\circ} 108$, mayo-agosto 2020, págs. 247-281 


\subsection{La separación entre órgano legislativo y constituyente}

El artículo $168 \mathrm{CE}$ determina que tras la aprobación del principio de reforma constitucional deberá procederse a la disolución de las Cortes y a la consiguiente convocatoria de elecciones para la elección de unas nuevas Cortes. Desde la doctrina se ha señalado que dicho trámite de intervención de dos legislaturas complejiza en exceso el procedimiento y es innecesario debido a la obligatoriedad del control ciudadano a través del referéndum ${ }^{96}$. El Consejo de Estado en su informe sobre la reforma constitucional de 2006, tras realizar un análisis comparado de una previsión de estas características en los sistemas constitucionales de nuestro entorno y nuestra propia historia constitucional, subrayó que el objeto de la primera legislatura es «establecer las razones de la reforma, delimitar su ámbito y precisar su alcance, habilitando en consecuencia a la legislatura siguiente para actuar como legislatura constituyente dentro de esos limites concretos». Por el contrario, en el caso de planteamiento de una reforma total de la Constitución, las primeras Cortes que la activan no pueden imponer límites materiales a las segundas, que el Consejo de Estado define como constituyentes, y deben ser éstas las que, electas especialmente tras una campaña electoral centrada en las diferentes propuestas de reforma, lleven a cabo dicha tarea. Carece de sentido pensar que un órgano constituido puede establecer límites a un órgano constituyente.

Asumiendo que, efectivamente, las labores constituyentes tiene que desarrollarlas un órgano electo al efecto, quedaría por resolver el debate de si es más conveniente que dicho órgano sea un órgano creado ad hoc, separado en sus funciones del órgano legislativo o si es conveniente que se proceda como está establecido en nuestro texto constitucional. La doctrina especializada en constitution-making se encuentra dividida en torno a la cuestión. Una parte de la misma, asumida en el caso español por García Roca $^{97}$ y Vera Santos ${ }^{98}$, señala que no conviene producirse tal separación debido, esencialmente, a la falta de seguridad jurídica de los órganos constituyentes, los cuales suelen escapar al control jurisdiccional al tratarse de órganos considerados soberanos cuyos poderes están por encima de los del resto del Estado ${ }^{99}$. A ello, además, ha de sumarse que es previsible que un órgano ad hoc reproduzca las mismas mayorías del órgano legislativo, con lo que el resultado final será el mismo con la consiguiente

${ }^{96}$ Aláez Corral, B. (2018). El procedimiento de reforma constitucional cuarenta años después. En R. Punset Blanco, L. Álvarez Álvarez, \& J. M. Roca Martínez (Eds.), Cuatro decadas de una Constitución normativa (1978-2018): Estudios sobre el desarrollo de la Constitución Española (pp. 639-667). Madrid, p. 653.

97 García Roca, J. (Ed.). (2014). El procedimiento de reforma constitucional. Pamplona: Aranzadi.

98 Vera Santos, J. M. (2016). La reforma del procedimiento de refoma constitucional en España. Revista de Derecho Político, 96, p. 44.

99 Landau, D. (2013a). Abusive constitutionalism. U.C. Davis Law Review, 47(1), 189-260; Partlett, W. (2012). The dangers of popular constitution-making. Brooklyn Journal of International Law, 38(1), 193-238. 
pérdida de tiempo en su constitución y puesta en funcionamiento y el elevado gasto que lleva aparejado.

En sentido contrario, puede argumentarse señalando que la separación entre órgano constituyente y legislativo obedece a dos motivos. En primer lugar, como prontamente identificaron los revolucionarios norteamericanos al crear órganos especiales diferenciados del legislativo ordinario para la redacción de sus primeras constituciones, puesto que no conviene dejar en manos del legislativo el desarrollo de un texto cuya función esencial es el control del poder político. Si un texto constitucional se diferencia de un texto legislativo en que el primero es la expresión del poder constituyente, mientras que el segundo es expresión de los representantes electos dentro de un marco jurídico definido, es necesario un órgano diferenciado del legislativo para la redacción del texto constitucional ${ }^{100}$. En este sentido, el poder constituyente, en tanto poder soberano, ha de expresarse a través de sus representantes en un órgano electo para cumplir con el cometido de redactar la Constitución sin interferencias de los poderes constituidos ${ }^{101}$. Y viceversa, el órgano constituyente no debe interferir en el trabajo de los poderes constituidos, los cuales también están legitimados democráticamente para ejercer sus funciones. Así, durante el periodo constituyente la actividad ordinaria del Estado debe continuar inalterada. Incluso, en el caso de que el país requiera de la adopción de una serie de medidas urgentes para enderezar la situación económica y social tendrán que ser los poderes constituidos los que dentro de las atribuciones que les sean otorgadas de acuerdo con el marco jurídico vigente traten de poner remedio a la situación. De esta forma, se produce una convivencia entre órganos legitimados democráticamente cuyas funciones no deben solaparse ${ }^{102}$.

En segundo lugar, la separación entre órganos obedece también a causas organizativas $^{103}$. Encargar a una comisión del legislativo ordinario la redacción del anteproyecto de Constitución, si bien puede mejorar la operatividad y la facilidad en la toma de decisiones, merma, por un lado, la plasmación de ideas de la pluralidad de la cámara en el anteproyecto. Y, por otra parte, impide tener una cámara centrada en llevar adelante el proyecto de Constitución, realizando trabajo especializado en diferentes comisiones, las cuales a su vez pueden recopilar y atender mejor las propuestas y proyectos presentados por ciudadanos individuales y organizaciones de la sociedad civil.

100 Kruman, Marc W. (1997). Between authority and liberty : state constitution making in revolutionary America. Chapel Hill : University of North Carolina Press.

101 Brandt, M., Cottrell, J., Ghai, Y., \& Regan, A. (2011). Constitution-making and reform. Interpeace, p. 235.

102 Viciano Pastor, R. (2012). La activación política del poder constituyente en España y sus cauces jurídicos. En R. Viciano Pastor (Ed.), Por una Asamblea Constituyente (pp. 130-146). Madrid: Sequitur, p. 145 .

103 Elster, J. (2012). Clearing and strengthening the channels of constitution making. En T. Ginsburg (Ed.), Comparative constitutional desing (pp. 15-30). New York: Cambridge University Press, p. 155; Mueller, D. C. (1996). Constitutional Democracy. New York: Oxford University Press, p. 317.

(C) UNED. Revista de Derecho Político

273

N. ${ }^{\circ} 108$, mayo-agosto 2020, págs. 247-281 


\subsection{La mayoría requerida para la aprobación del nuevo texto constitucional por parte del órgano constituyente}

El artículo 168.2 CE establece que la mayoría para la aprobación del nuevo texto constitucional debe ser de dos tercios en ambas cámaras. Este requisito constituye una innovación de la Constitución frente al procedimiento adoptado tradicionalmente en procesos constituyentes como el francés de 1946 o el propio español de $1978^{104}$. Aparentemente, no cabría mucho debate sobre dicho extremo al entenderse que si las reformas constitucionales requieren, por norma general, mayorías agravadas, ha de imponerse el mismo requisito para la adopción de la misma ${ }^{105}$. No obstante, cabría preguntarse la conveniencia de que se repita en la segundas Cortes el criterio de los dos tercios para la aprobación final del texto, puesto que ya se habría producido en la primera legislatura a aprobar el principio de reforma por dicha mayoría. A pesar de que no se le nombre en la Constitución como un órgano constituyente propiamente dicho, no cabe duda de que la segunda legislatura ejercerá funciones constituyentes y que ésta se compondrá por los diputados y senadores electos en el marco de unas elecciones que girarán en torno a diferentes propuestas de texto constitucional. Así, en tanto que las segundas Cortes tienen funciones cuyas semejanzas son muy cercanas a las de una asamblea constituyente, cabe la comparación con un órgano constituyente propiamente dicho. Algunos ejemplos destacados entre las experiencias constituyentes que se han producido en los últimos años, pueden aconsejar retomar el criterio clásico de aprobación por mayoría absoluta en las segundas Cortes. En los procesos constituyentes boliviano de 2006-2009 y los procesos nepalíes de 2008-2012 y 20142018, se estimó que convenía una mayoría de dos tercios en la asamblea constituyente para la aprobación de la Constitución puesto que ello forzaría la obtención de consensos entre las diferentes fuerzas políticas y evitaría que el texto constitucional fuera la traslación del programa de una fuerza política con mayoría absoluta. Sin embargo, lo que ocurrió en la práctica fue el que el tercio minoritario de la asamblea constituyente evitó precisamente que se produjera dicho consenso y puse en jaque la continuidad del proceso. En este sentido, dichas experiencias evidencian que una mayoría de dos tercios puede terminar por bloquear el proceso y permite que una minoría pueda imponer su criterio amenazando con dinamitar el proceso. Así, desde este punto de vista, la deseable toma de decisiones consensuada no debe ser óbice para que la voluntad mayoritaria prevalezca evitando que se produzca el obstruccionismo de las minorías $^{106}$.

104 Véase el artículo 123.3 del Reglamento provisional del Congreso de los Diputados de 17 de octubre de 1977. Boletín Oficial del Estado, número 256 de 26 de octubre de 1977.

105 Elster, J. (2012). The optimal design of a constituent assembly. En H. Landemore (Ed.), Collective wisdom: Principles and Mechanisms (pp. 148-172). Cambridge: Cambridge University Press, p. 168.

106 Viciano Pastor, R. (2012). La activación política del poder constituyente en España y sus cauces jurídicos. En R. Viciano Pastor (Ed.), Por una Asamblea Constituyente (pp. 130-146). Madrid: Sequitur, p. 145. 
Con la finalidad de evitar que la Constitución resultante sea aprobada únicamente por el grupo político que pueda contar con la mayoría absoluta, y al margen de establecer un sistema electoral que genere efectos proporcionales y que limite las posibilidades de que se produzca dicha situación ${ }^{107}$, podría optarse por una solución intermedia entre la vigente y la planteada. Tal y como se estableció en un proceso constituyente tan recurrentemente alabado por la doctrina como el sudafricano de 1993-1996, aquellas materias en la que los representantes no alcancen mayorías de dos tercios podrían ser sometidas a referéndum. Como el caso de Sudáfrica demuestra, este mecanismo fomenta la obtención de consensos amplios: los partidos minoritarios se mostraron más predispuestos a alcanzar acuerdos con el partido mayoritario, el Congreso Nacional Africano, puesto que éstos eran conscientes que de producirse un referéndum saldría presumiblemente vencedora la postura defendida por el Congreso Nacional Africano y al menos en el seno de la Asamblea Constituyente tenían margen para llegar a un mejor acuerdo ${ }^{108}$.

\subsection{El control previo de constitucionalidad de la reforma constitucional por parte del Tribunal Constitucional}

Entre las propuestas de reforma del Título X destaca, por tratarse de un elemento que supondría una importante novedad respecto al texto actual, la introducción del control previo de constitucionalidad de las reformas constitucionales. Para los autores que lo proponen, el control debe ser previo para evitar un choque de legitimidades con el poder constituyente en caso de aprobación de la reforma y debe producirse para evitar, en caso de introducción de cláusulas de intangibilidad, que se violen los límites materiales fijados ${ }^{109}$ y para aportar un «auxilio complejo» a los ciudadanos ante una reforma de tal complejidad ${ }^{110}$. Otros autores, asumiendo que la reforma constitucional se lleva a cabo por ley ${ }^{111}$, entienden que no sería necesaria una reforma constitucional para introducir dicho extremo, sino que bastaría con una reforma de la LOTC que la contemplase ${ }^{112}$. En sentido contrario, argumentando que una reforma constitucional no es un norma con rango de ley, se ha subrayado que únicamente cabría la posibili-

${ }^{107}$ Landau, D. (2013b). Constitution-making gone wrong. Alabama Law Review, 64(5), p. 962.

108 Ghai, Y. (2006). La asamblea constituyente en la elaboración de la constitución política. Estocolmo: International Institute for Democracy and Electoral Assistance, p. 38.

109 Tajadura Tejada, J. (2016). La reforma de la Constitución (arts. 166-169). En T. Freixes Sanjúan \& J. C. Gavara de Cara (Eds.), Repensar la constitución. Ideas para una reforma de la Constitución de 1978: reforma y comunicación dialógica (pp. 257-281). Madrid: Boletín Oficial del Estado, p. 277.

110 Balaguer Callejón, M. L., \& Trujillo Pérez, A. J. (2018). Título X. De la reforma constitucional. En Y. Gómez Sánchez (Ed.), Estudios sobre la reforma de la Constitución de 1978 en su Cuarenta Aniversario (pp. 427-440). Pamplona: Aranzadi, p. 435.

111 Pérez Royo, J. (1987). La reforma de la Constitución. Madrid: Publicaciones del Congreso de los Diputados, p. 183.

112 García-Escudero Márquez, P. (2008). El procedimiento agravado de reforma de la Constitución de 1978. Revista de Derecho Político, 71-72, p. 192.

(C) UNED. Revista de Derecho Político

N. ${ }^{\circ} 108$, mayo-agosto 2020, págs. 247-281 
dad de «admitir un cierto control previo de los actos de los órganos competentes en el procedimiento hasta el momento de la adquisición por la norma del carácter constitucional» ${ }^{113}$.

Veamos de nuevo como ha resuelto la cuestión el TJUE. En el caso Pringle citado anteriormente, el TJUE (FFJJ 30 y ss.) entendió, en primer lugar, que, de acuerdo con el artículo 267 TFUE, está capacitado para pronunciarse sobre la validez de un acto adoptado por una institución de la Unión, en este caso del Consejo Europeo, reconocido entre las instituciones de la Unión en el artículo 13.1 TEU. Esto es, a pesar de que el examen de la validez del Derecho primario no forma parte de la competencia del Tribunal de Justicia, se estableció la posibilidad de control sobre un acto de una institución de la Unión, independientemente de si ésta se tratara de un acto legislativo o de cualquier otro tipo. En segundo lugar, el Tribunal señaló que, dado que el artículo 48.6, que regula la reforma simplificada de los Tratados, establece dos límites al uso de dicho procedimiento (cuando se trate necesariamente de proyectos de revisión de la totalidad o afecte a las disposiciones de la tercera parte del TFUE y el no aumento de las competencias atribuidas a la Unión), debe poder procederse tanto a un control formal como sustancial de la reforma puesto que la reforma aprobada puede haber implicado no sólo un incumplimiento formal del procedimiento de reforma, sino también sustancial al haber podido traspasar los límites materiales establecidos en el mismo. Cuestión diferente, señala también el Tribunal, es que dicha reforma se hubiese llevado vía el procedimiento de reforma ordinaria, esto es, a través de una Convención o una Conferencia intergubernamental. En ese caso, el Tribunal no podría ser competente para llevar a cabo un control de carácter formal de la reforma observando si se han cumplido los requisitos formales establecidos puesto que no se trata de una de las instituciones de la Unión cuyos actos son susceptibles de control ${ }^{114}$. Esto es, el TJUE establece una clara separación entre el control que se puede llevar a cabo sobre los actos de los poderes constituidos y los que, salvando las diferencias entre una Convención europea y una asamblea constituyente, lleve a cabo el poder constituyente.

En la línea del criterio establecido por el TJUE, parece entonces razonable señalar que únicamente debe poder llevarse a cabo producirse un control sustancial de la reforma en caso de que se pretenda comprobar que ésta no excede los límites establecidos en el texto constitucional. Por control sustancial aquí no cabe entender un control sobre el contenido de la reforma, sino sobre la vigilancia de que la misma no sobrepasa los límites materiales establecidos. Para el caso en que se produzca una reforma mediante el artículo 168, esto es, mediante la convocatoria de un órgano electo con funciones constituyentes, cabrían dos posibilidades. En caso de que el principio de reforma aprobado en las primeras Cortes hubiese determinado los límites

113 De Cabo Martín, C. (2003). La reforma constitucional en la perspectiva de las fuentes del derecho. Madrid: Trotta, p. 70.

114 Aguilar Calahorro, A. (2014). La decisión Pringle en el proceso de constitucionalización de la Unión Europea. Revista Española de Derecho Constitucional, (101), 337-380. 
a los que ésta debe someterse en las segundas cortes, podrá producirse un control sustancial en el sentido señalado. De aprobarse un principio de reforma total de la Constitución, no podrá realizarse más que un control formal de la reforma.

\subsection{La corrección del artículo 169}

El artículo 169 de la Constitución establece que «no podrá iniciarse la reforma constitucional en tiempo de guerra o de vigencia de alguno de los estados previstos en el artículo 116». No obstante, como advierte la práctica totalidad de la doctrina que ha entrado a reflexionar sobre estas cuestiones ${ }^{115}$, este precepto conlleva que, si el procedimiento de reforma se ha iniciado antes de un tiempo de guerra o antes de que se declare el estado de alarma, excepción y sitio, este puede continuar sin ningún tipo de limitación. Sin embargo, no parece conveniente que se realice una reforma constitucional en caso de encontrarse declarado alguno de los citados estados de excepción o en tiempo de guerra, por lo que sería más conveniente que el artículo establezca la prohibición de tramitación de una reforma constitucional en dichos casos.

Asimismo, podría considerarse eliminar, parafraseando lo que plantea Aláez Corral, la referencia al estado de alarma al no afectar éste al normal funcionamiento de las instituciones del Estado ni conllevar suspensión de derechos fundamentales ${ }^{116}$. El estado de alarma, cuya activación puede ser acordada por el Gobierno mediante decreto por un plazo de quince días sin la autorización del Congreso, puede incluso ser una herramienta por parte del Gobierno para frenar una posible reforma constitucional. Esta situación es, desde luego, harto improbable dado que las mayorías requeridas para la reforma hacen pensar que el Gobierno no va a frenar una iniciativa de reforma constitucional del o los grupos parlamentarios que le dan soporte. No obstante, no es una situación imposible y convendría tenerla presente ${ }^{117}$.

115 Es el caso, por ejemplo, de Aláez Corral, B. (2018). El procedimiento de reforma constitucional cuarenta años después. En R. Punset Blanco, L. Álvarez Álvarez, \& J. M. Roca Martínez (Eds.), Cuatro decadas de una Constitución normativa (1978-2018): Estudios sobre el desarrollo de la Constitución Española (pp. 639-667). Madrid, p. 657; Tajadura Tejada, J. (2016). La reforma de la Constitución (arts. 166169). En T. Freixes Sanjúan \& J. C. Gavara de Cara (Eds.), Repensar la constitución. Ideas para una reforma de la Constitución de 1978: reforma y comunicación dialógica (pp. 257-281). Madrid: Boletín Oficial del Estado, p. 278; Vera Santos, J. M. (2016). La reforma del procedimiento de refoma constitucional en España. Revista de Derecho Político, (96), p. 24; Pérez Royo, J. (1996). Artículo 169:Límites a la iniciativa de reforma. En Ó. Alzaga Villaamil (Ed.), Comentarios a la Constitución Española. Tomo XII (pp. 507-514). Madrid: Cortes Generales, p. 507.

116 Aláez Corral, B. (2018). El procedimiento de reforma constitucional cuarenta años después. En R. Punset Blanco, L. Álvarez Álvarez, \& J. M. Roca Martínez (Eds.), Cuatro decadas de una Constitución normativa (1978-2018): Estudios sobre el desarrollo de la Constitución Española (pp. 639-667). Madrid, p.657.

117 Dicha cuestión fue también objeto de debate en las Cortes Constituyentes. El representante del grupo comunista, Solé Tura, señaló que el sentido del artículo era evitar una reforma de la Constitución a través de la declaración de alguno de los citados estados. Por su parte, Fraga Iribarne recalcó que es

(C) UNED. Revista de Derecho Político

277

N. ${ }^{\circ} 108$, mayo-agosto 2020, págs. 247-281 


\section{UNA PROPUESTA CONCRETA DE NUEVO ARTICULADO DEL TÍTULO X}

De acuerdo con todas las aportaciones y debates doctrinales que se han ido deshilando, esbozaré, para finalizar, una propuesta de articulado del Título X. El objeto aquí, como lo ha sido durante todo el artículo, es el de contribuir al debate doctrinal en torno a la cuestión aportando un punto de vista que no ha sido desarrollado doctrinalmente hasta el momento.

En primer lugar, por lo que respecta al contenido del artículo 166, debería ampliarse el número de sujetos legitimados en materia de reforma constitucional, añadiéndose a un porcentaje de ciudadanos equivalente al de la Iniciativa Legislativa Popular. Ahora bien, siguiendo el ejemplo de las experiencias de Suiza y de EEUU, la iniciativa popular de reforma constitucional debería realizarse sin mediación de los poderes constituidos, pudiendo los ciudadanos plantear directamente a referéndum una propuesta de reforma o, como se desarrollará después, de convocatoria de un órgano constituyente ad hoc que proceda a una reforma total de la Constitución. En caso de que los impulsores de la reforma sean cualesquiera otros de los sujetos legitimados en el artículo $87 \mathrm{CE}$, se procedería a la misma como hasta el momento. En cualquiera de los casos, sea cual sea el sujeto impulsor de la reforma, se le otorgaría prioridad sobre cualquier otro asunto.

En segundo lugar, por lo que respecta al artículo 167, de acuerdo con lo desarrollado hasta el momento, convendría unificar los procedimientos de reforma parcial en un único mecanismo, independientemente de la parte del articulado de que se trate. Esto es, se eliminaría cualquier diferenciación por cuestión de materia, evitando así crear jerarquías entre preceptos constitucionales. La mayoría requerida habría de seguir siendo la vigente, de tres quintos. Como se ha señalado desde la doctrina, es una mayoría que ha demostrado un punto de equilibrio óptimo entre rigidez y flexibilidad. Asimismo, como en el caso del vigente artículo 168, cualquier modificación por la vía de este artículo requeriría de un referéndum de ratificación. Este procedimiento lo podrían activar directamente un número de ciudadanos equivalente al establecido para la Iniciativa Legislativa Popular. Los impulsores de la reforma a través de la iniciativa popular deberían presentar un texto articulado de propuesta de reforma para la aprobación por parte de sus conciudadanos.

En tercer lugar, el artículo 168 tendría por finalidad regular el procedimiento de reforma total de la Constitución mediante la convocatoria de un órgano constituyente ad hoc. Para proceder a su convocatoria, como en el artículo vigente, debería aprobarse

incongruente pensar que la mayoría que daría inicio al proceso de reforma es la misma que podría considerar declarar alguno de los estados previstos en el artículo 116 para bloquearla. Asimismo, el representante de Alianza Popular subrayó que el verdadero riesgo no es tanto que se impida la reforma de la Constitución, sino que ésta se lleve a cabo en un momento de grave excepcionalidad. Véase al respecto Pérez Royo, J. (1987). La reforma de la Constitución. Madrid: Publicaciones del Congreso de los Diputados, p. 511. 
el principio de reforma por dos tercios de ambas Cámaras y someterse dicha decisión a referéndum. El referéndum constaría de dos preguntas: una relativa a la apertura del proceso de reforma total y otra acerca de la reglamentación del proceso electoral y el funcionamiento y funciones del órgano constituyente. De aprobarse ambas materias, se procedería a la convocatoria de elecciones al órgano constituyente. El mismo tendría como objetivo único la redacción, aprobación y sometimiento a referéndum del nuevo texto constitucional. La aprobación por mayoría de la Cámara del principio de reforma se volvería inútil dado que hay un mandato popular previo. En el momento en que el órgano constituyente cumpliera con su tarea, previa aprobación del texto por mayoría absoluta de sus miembros, se procedería a su automática disolución. De resultar negativo el resultado del referéndum o de sobrepasarse en el tiempo fijado para el desarrollo de sus trabajos, se procedería igualmente a la disolución del órgano constituyente. El Parlamento continuaría con sus trabajos hasta el momento de ratificación en referéndum del nuevo texto sin interferir en las labores del órgano constituyente. Una vez se ha producido la ratificación en referéndum del nuevo texto, se decretaría la disolución inmediata de las Cortes y la convocatoria de nuevas elecciones de acuerdo a las nuevas disposiciones constitucionales. En caso de que el impulso de la reforma total procediera de un número de ciudadanos equivalente al establecido para la Iniciativa Legislativa Popular, estos deberían plantear la activación del principio de reforma total y una propuesta de reglamentación del proceso electoral y funcionamiento y funciones del órgano constituyente.

En cuarto y último lugar, el articulo 169, en consonancia con lo que ha establecido en forma prácticamente unánime la doctrina, debería añadir que no podría llevarse a cabo un proceso de reforma constitucional en caso de que se haya declarado con posterioridad al inicio de la misma el estado de excepción y de sitio. Se eliminarían además los posibles riesgos asociados a la declaración por parte del Gobierno del estado de alarma.

Por lo que respecta a la reforma de los Reglamentos de las Cámaras conformes a la Constitución vigente, a modo de resumen, se ha planteado el establecimiento de un verdadero procedimiento especial para el caso de reforma constitucional. En el caso de reforma a través del artículo 167, convendría establecer la prohibición del procedimiento de urgencia y lectura única y la prioridad de la propuesta de reforma constitucional sobre cualquier otro asunto. En cuanto al procedimiento de reforma a través del artículo 168, se ha planteado introducir los siguientes mecanismos relativos a los trabajos de la segunda legislatura: trabajo en diversas comisiones temáticas, publicación semanal del proyecto de Constitución, recolección de propuestas mediante medios diversos y debate en Pleno o en comisión de aquellas que tengan mayor aceptación social, posibilidad de planteamiento de textos alternativos por parte de un número representativo de ciudadanos o de representantes, introducción de un máximo temporal para el desarrollo de los trabajos de la segunda legislatura, disolución automática de las Cortes y convocatoria de nuevas elecciones tras finalización de los trabajos de la segunda legislatura. 
Title:

Some gradual proposals for democratizing the Constitutional reform procedure

Table of contents:

1. INTRODUCTION. 2. CONSTITUTION AND CITIZEN PARTICIPATION. 3. THE REFORM OF THE RULES OF PROCEDURE OF THE CHAMBERS. 3.2. PROHIBITION OF THE PROCEDURE OF URGENCY AND SINGLE READING IN THE CASE OF REFORM THROUGH ARTICLE 167. 3.2. THE INTRODUCTION OF PARTICIPATORY MECHANISMS AND TRANSPARENCY IN THE CASE OF REFORM THROUGH ARTICLE 168. 4. RECONSIDERATION BY ARTICLES OF THE REFORM PROCEDURE ESTABLISHED IN THE CONSTITUTION. 4.1. INTRODUCTION OF THE INITIATED CONSTITUTIONAL AMENDMENT AND TO CALL A CONSTITUENT ASSEMBLY. 4.2. OBLIGATORY REFERENDUM IN CASE OF ACTIVATION OF THE REFORM PROCEDURE OF ARTICLE 167 EC. 4.3. THE UNNECESSARY DETERMINATION OF ONLY SOME PRECEPTS TO BE SUBJECT TO PARTIAL REFORM THROUGH ARTICLE 168. 4.4. THE SEPARATION BETWEEN LEGISLATIVE AND CONSTITUENT BODY. 4.5. THE MAJORITY REQUIRED FOR THE APPROVAL OF THE NEW CONSTITUTIONAL TEXT BY THE CONSTITUENT BODY. 4.6. THE PRIOR CONSTITUTIONAL CONTROL OF CONSTITUTIONAL REFORM BY THE CONSTITUTIONAL COURT. 4.7. THE CORRECTION OF ARTICLE 169. 5. A SPECIFIC PROPOSAL OF A NEW TITLE X.

\section{Resumen:}

En los últimos años, una parte de la doctrina constitucional española ha centrado su atención en el procedimiento de reforma constitucional de la Constitución española de 1978 planteando diversas propuestas de reforma. La práctica totalidad de los investigadores que han dedicado esfuerzos a la cuestión lo han hecho partiendo de una concepción de Constitución de acuerdo con la cual el proceso por el cual se conforma es considerado secundario, cuando no irrelevante, o restando importancia a la posibilidad de participación ciudadana directa. El objeto de este artículo es plantear una serie de propuestas graduales de democratización del procedimiento de reforma constitucional desde un enfoque diferenciado del de la mayoría de la doctrina. Por un lado, se asume que una Constitución no se caracteriza únicamente por ser un conjunto de normas fundamentales que encabezan un ordenamiento jurídico, sino que es un texto que, para ser tal, requiere de un procedimiento democrático y participativo en el que pueda hacerse efectiva la máxima según la cual una Constitución es un acuerdo de la sociedad sobre cómo debe regirse y gobernarse el Estado. Por otro lado, la metodología de análisis que se emplea, prácticamente inexplorada por la 
doctrina española, parte de los análisis del campo de estudio comúnmente conocido como constitution-making. Derivado de ello, los resultados a los que se llega difieren sustancialmente de lo planteado hasta el momento.

\title{
Palabras clave:
}

constitution-making, democracia participativa, poder constituyente, reforma constitucional

\begin{abstract}
:
In recent years, a part of the Spanish constitutional doctrine has focused its attention on the procedure of constitutional reform of the Spanish Constitution of 1978 suggesting diverse reform proposals. Practically all of the researchers who have dedicated efforts to this issue start their analysis from a conception of the Constitution according to which the constitution-making process is considered secondary, if not irrelevant, or playing down the possibility of direct citizen participation. The goal of this article is to present a series of gradual proposals for democratizing the constitutional reform procedure from a differentiated approach of the one commonly defended by the majority of the Spanish doctrine. On the one hand, usually, scholars depict a Constitution as the set of fundamental norms that characterize any legal order. In this article I begin from a different standpoint assuming that a Constitution requires a democratic and participatory procedure in order to make reality the principle according to which a Constitution is an agreement of society on how the State should be governed. On the other hand, the methodology of analysis that is used, practically unexplored by the Spanish doctrine, is growing field of study of the constitution-making analyisis. Therefore, the results achieved differ substantially from what has been proposed up to now.
\end{abstract}

\section{Keywords:}

constitution-making, participatory democracy, constituent power, constitutional reform 
